RAND EUROPE

\title{
COVID-19 and the cost of vaccine nationalism
}

Marco Hafner, Erez Yerushalmi, Clement Fays,

Eliane Dufresne, Christian van Stolk

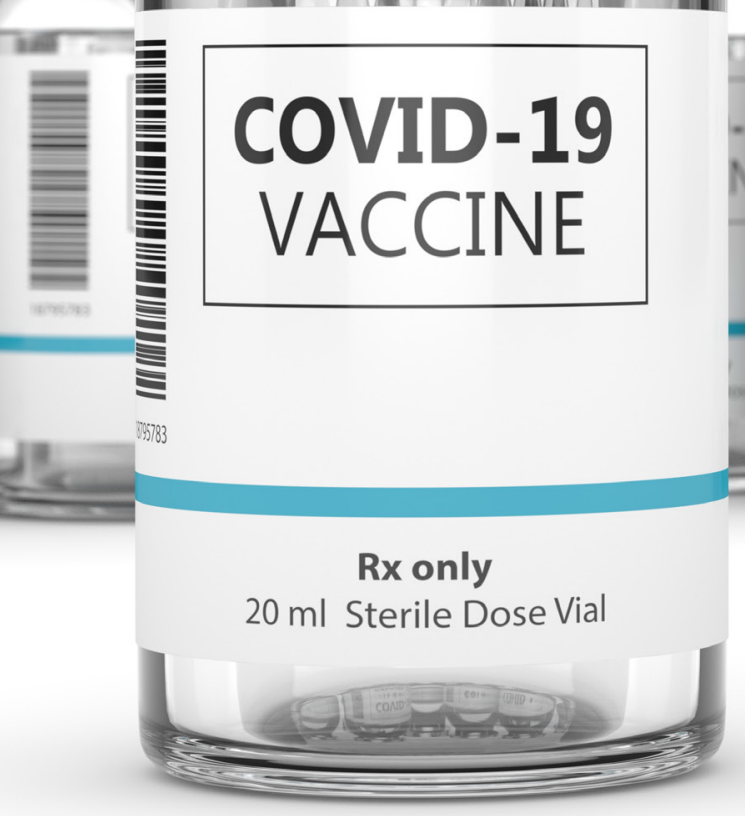


For more information on this publication, visit www.rand.org/t/RRA769-1

Published by the RAND Corporation, Santa Monica, Calif., and Cambridge, UK

(c) Copyright 2020 RAND Corporation

RAND $\AA$ is a registered trademark.

RAND Europe is a not-for-profit research organisation that helps to improve policy and decision making through research and analysis. RAND's publications do not necessarily reflect the opinions of its research clients and sponsors.

\section{Limited Print and Electronic Distribution Rights}

This document and trademark(s) contained herein are protected by law. This representation of RAND intellectual property is provided for noncommercial use only. Unauthorized posting of this publication online is prohibited. Permission is given to duplicate this document for personal use only, as long as it is unaltered and complete. Permission is required from RAND to reproduce, or reuse in another form, any of its research documents for commercial use. For information on reprint and linking permissions, please visit www.rand.org/pubs/permissions.

\section{Support RAND}

Make a tax-deductible charitable contribution at www.rand.org/giving/contribute

www.rand.org www.randeurope.org 


\section{Preface}

This study was conducted by RAND Europe. Funding was made possible by the independent research and development provisions of RAND's contracts for the operation of its U.S. Department of Defense federally funded research and development centers.

RAND Europe, an affiliate of the RAND Corporation, is a not-for-profit organisation whose mission is to help improve policy and decision making through research and analysis. Over the last 30 years, we have provided objective research and analysis to serve the policy needs of governments, institutions, charities, foundations, universities and the private sector.

For more information please contact:

RAND Europe

Westbrook Centre

Milton Road

Cambridge CB4 1YG

United Kingdom

+44 (1223) 353329 



\section{Executive summary}

COVID-19, caused by severe acute respiratory syndrome coronavirus 2 (SARS-CoV-2), publicly emerged in late December 2019 in the Chinese province of Wuhan and has since then rapidly spread to other countries in Asia, Europe, North America and the rest of the world. More than 30 million people worldwide are already confirmed to have been infected, and over 1 million have lost their lives. As well as the associated health burden, the COVID-19 outbreak has also caused substantial damage to the global economy.

Until there is a vaccine, or other treatment widely available, physical distancing, the use of face masks and test, track and trace will most likely be the only effective measures in the battle against the spread of the disease. There is an unprecedented global research effort ongoing to find a vaccine against SARS-CoV-2. Currently there are more than 165 vaccines being developed, with some already in human trials.

Experience from the $2009 \mathrm{H} 1 \mathrm{~N} 1$ pandemic and the onset of the COVID-19 pandemic suggests that in responding to such events, national governments tend to follow their own interests instead of pursuing a more globally coordinated approach. A situation where countries push to get first access to a supply of vaccines and potentially hoard key inputs for vaccine production has been commonly referred to as 'vaccine nationalism'. A lack of global coordination and cooperation could have negative consequences for how well the global pandemic is managed and contained. While international institutions such as the World Health Organization, the United Nations and the Global Alliance for Vaccines and Immunization, among others, are trying to support the multilateral option to coordinate globally the COVID-19 vaccine effort, some of the world's leading economies such as the United States have been reluctant to commit and invest into these coordinated efforts.

In this study, we examine some of the negative consequences that vaccine nationalism could have in terms of how well we manage the pandemic in the future once a vaccine has been developed. Another objective is to understand the potential economic implications that could arise if countries follow a nationalistic behaviour with regard to the development, manufacturing and distribution of future COVID-19 vaccines. To this end, we use a macroeconomic model where all countries in the world are interlinked with each other through trade in goods and services as well as investment. The model allows us to put the world economy into a laboratory and run different 'what-if' experiments, in order to examine what would happen to global economic output if no vaccine was developed or if only a few countries or regions managed to immunise their own populations. 


\section{Vaccine nationalism adversely affects how well the public health crisis can be managed}

Vaccine nationalism can have several negative implications for the production and equitable distribution of potential vaccines across the world.

Firstly, the race observed between superpowers such as the US, China and Russia for who is going to develop a vaccine first could help to drive the successful development of potential vaccines. However, the geopolitical competition could also induce countries to speed up their trials and, to satisfy public demand, push for quicker and riskier regulatory approvals. If it transpires that some of these vaccines are not effective or have severe side-effects, that could further erode public trust in vaccines and complicate national vaccination plans.

Secondly, the current public focus is on the development of the vaccine. However, once there are safe and effective vaccine candidates available, they need to be produced and administered at scale. Vaccine manufacturing is a complex process. The infrastructure needed will depend on the type of vaccine developed and there is also the challenge that poorer countries may not have adequate systems to deliver and administer doses that have been manufactured in different environments, mostly found in the wealthier countries. Moreover, components for a vaccine usually come from different geographical locations that specialise in specific stages of the production process. A 'nationalistic' approach to vaccine production could lead to global vaccine supply chains being interrupted if some countries hoard the key inputs, causing production delays.

Thirdly, in order to secure access to a vaccine, many governments, mostly from wealthier countries, have signed direct bilateral deals with producers of vaccine candidates in order to secure a stock for their own population. This patchwork of bilateral agreements could adversely affect pricing and availability of potential vaccines as wealthier countries bid for limited vaccine supplies. A 'my nation first' approach could lead to an inefficient allocation of early available vaccines, potentially favouring individuals at less risk in high-income countries over high-risk individuals in poorer countries.

There are ongoing international efforts to coordinate a global COVID-19 response. These include the COVAX Facility, a cooperation between the WHO and other international institutions such as the Global Alliance for Vaccines and Immunization, which aims to provide equal access to vaccines globally by pooling resources. However, these facilities have initially been suffering from weak commitments from wealthier countries. While the COVID-19 crisis is foremost a public health crisis, it's also an economic crisis, with national governments spending trillions of dollars on fighting the negative economic impact. But if the virus is not under control in all regions of the world, global economic demand will most likely still be impaired and global supply chains interrupted.

\section{Without a vaccine the prolonged economic cost of COVID-19 could be profound}

Until there is a widely available vaccine for COVID-19, or any other treatment, physical distancing regulations and measures will continue to affect key sectors of the economy negatively, especially those that rely on close physical proximity between people. As part of our economic 
analysis, we therefore have modelled the impact on global GDP of reduced activity induced by physical distancing and changes in consumer behaviour in the following highly contact-intensive service sectors: (1) hospitality; (2) recreation; (3) retail and wholesale; (4) transportation; and (5) health and social care. In the analysis, we examine how GDP varies across several scenarios, which differ in their assumptions about which countries have access to a vaccine. We take as a benchmark for comparison a hypothetical baseline scenario where every country in the world manages to immunise sufficiently its population and physical distancing rules and regulations can be eased, allowing economic activity in contact-intensive sectors to gradually resume to levels experienced before the pandemic.

In one scenario, we examine how the world economy would evolve in the absence of vaccines that would sufficiently immunise populations against the virus and would allow the five contactintensive sectors we model to come gradually back to normal activity. We estimate that, depending on the assumptions made about the impact of COVID-19 on contact-intensive service sectors, about \$3.4 trillion globally in GDP terms could be lost annually, even in the absence of large-scale containment and closure measures as experienced during the first months of the pandemic in many countries. This corresponds to about 3.7 per cent of global GDP. Broken down by countries or regions, we estimate that the UK could lose about 4.3 per cent; the EU-27 about 5.6 per cent; and the US about 2.2 per cent of their annual GDP. The size of the effect varies across countries with regard to specific domestic demand and international trade conditions. For instance, the UK is a service-intensive economy and tourism is a very important sector for many countries within the EU-27. And even under the most conservative estimates, without a vaccine, the prolonged global GDP loss associated with lower economic activity in five highly contactintensive service sectors is about $\$ 1.4$ trillion annually, or 1.5 per cent of global GDP.

\section{Even if nationalistic behaviour is inevitable, there are economic incentives to provide access to vaccines across the globe as soon as possible}

In the economic analysis we examine scenarios which assume that some countries or regions miss out initially on access to vaccines. For instance, we estimate that if the countries that are currently actively developing a vaccine (e.g. USA, EU-27, UK, China, India and Russia) are successful in this endeavour and can inoculate a sufficiently large share of their population, the estimated loss for the world economy in GDP terms would reduce from 3.7 per cent to 1.3 per cent annually. However, the lack of access to vaccines for the rest of the world would still result in a GDP loss of about $\$ 1,232$ bn per year, or approximately about $\$ 103 \mathrm{bn}$ a month.

Furthermore, in a separate scenario analysis, we show that even if only the lowest-income countries have no access to a COVID-19 vaccine initially, the global economy would still lose about \$153bn a year. Under such a scenario, all high-income countries, as well as countries such as India, China and Russia, would still incur together an estimated GDP loss of about \$119bn a year, or approximately about $\$ 10 \mathrm{bn}$ a month, compared to a scenario where all countries have access to a vaccine and can inoculate their populations sufficiently. Based on sensitivity analysis the estimate varies between $\$ 49 \mathrm{bn}$ to $\$ 230 \mathrm{bn}$ a year, or about $\$ 4 \mathrm{bn}$ to $\$ 19 \mathrm{bn}$ a month. That is, our economic analysis suggests that there are distinct benefits associated with ensuring that 
countries have equitable access to the vaccines that are being developed. It also suggests that wealthier countries could channel significant funds into facilities that try to pool resources for an equitable global access to vaccines, such as COVAX, without being economically worse off.

Even though $\$ 49 \mathrm{bn}-\$ 230 \mathrm{bn}$ is a relatively small amount at face value, compared to what many countries currently are spending on government programmes to safeguard their economies during the pandemic, there is an economic incentive to provide access to vaccines to all as soon as possible. Previously, it has been estimated that the cost of procuring and delivering a safe and effective vaccine to the world's poorest countries would be about \$25n (Oxfam International 2020). Based on this cost estimate, our findings would suggest that investing in access to COVID19 vaccines for lower income countries represents a potentially sound strategy for wealthier countries, with a benefit-to-cost ratio of between 1.9 and 12.6; or in other words, every $\$ 1$ invested would provide an approximate return of between $\$ 1.9$ and $\$ 12.6$, with a base case value estimate of $\$ 4.8$. 


\section{Table of contents}

Preface

Executive summary iii

List of tables $\quad$ ix

Abbreviations $\quad x$

Acknowledgements $\quad$ xi

1. Introduction 1

1.1. Objectives 2

1.2. Methodological approach 2

1.3. The structure of this report 3

2. Background: the COVID-19 crisis and a lack of global coordination and cooperation 5

2.1. The global ('arms') race to deliver vaccines could harm public trust 6

2.2. Nationalistic behaviour could negatively affect global vaccine supply chains 7

2.3. International competition for vaccine supplies could negatively affect global affordability 7

2.4. Implications 9

3. Estimating the economic implications of vaccine nationalism 11

3.1. Modelling approach $\quad 12$

3.2. The modelling scenarios 19

3.3. The economic effects of inequitable access to COVID-19 vaccines on economic output 20

3.4. Implications 23

3.5. Limitations 24

4. Discussion 27

4.1. The availability of safe and effective vaccines is critical to mitigating the

4.2. The development and distribution of vaccines could be seen as global public goods 27

4.3. At present it is feared that global competition around vaccine allocation will

4.4. The cost of vaccine development and distribution is modest compared to the
likely prolonged economic costs associated with COVID-19

4.5. Even if nationalistic behaviour is inevitable, there are economic incentives to provide access to vaccines across the globe as soon as possible 30 
4.6. There may also be unintended consequences associated with global competition or vaccine nationalism

4.7. To foster international sharing of vaccines, there is a need for enforceable frameworks in vaccine development and distribution, managed by established international fora

References

Appendix A: The macroeconomic modelling framework

A.1. The macroeconomic model 41

A.2. The impact of COVID-related shocks on contact-intensive service sectors 44

A.3. Limitations of the modelling approach 54

Appendix B: Economic effects of inequitable access to COVID-19 vaccines by country (real annual GDP in \$bn) 


\section{List of tables}

Table 3.1. Countries and regions included in the analysis 15

Table 3.2. Sectors included in the analysis 16

Table 3.3. Assumed country- or region-specific changes in economic activity by
contact-intensive sector

Table 3.4. The modelling scenarios $\quad 19$

Table 3.5. Per cent change in real annual GDP relative to baseline - scenarios 1 to $4 \quad 20$

Table 3.6. Change in real annual GDP in \$bn relative to baseline - scenarios 1 to 4

Table A.1. Countries and regions included in the analysis 43

Table A.2. GTAP sectors included in the analysis 44

Table A.3. Sweden's production value index by sector, year-on-year changes by month 48

Table A.4. Assumed changes in $\Delta q_{S} \quad 49$

Table A.5. Estimated country- or region-specific adjustment parameter 51

Table A.6. Assumed country- or region-specific changes in $\Delta q_{s, i}$

Table A.7. Parameter value assumptions for sector-specific elasticities 53

Table B.1. Change in real annual GDP in \$bn relative to baseline scenario - EU-27 55

Table B.2. Change in real annual GDP in \$bn relative to baseline scenario - High-income

Table B.3. Change in real annual GDP in \$bn relative to baseline scenario - Middle-income countries 57

Table B.4. Change in real annual GDP in \$bn relative to baseline scenario - Low-income
countries 


\title{
Abbreviations
}

\author{
ACT Access to COVID Tools \\ AMC Advanced Market Commitment \\ CEPI Coalition for Epidemic Preparedness Innovations \\ CGE Computable General Equilibrium \\ GAVI Global Alliance for Vaccines and Immunization \\ GTAP Global Trade Analysis Project \\ GDP Gross Domestic Product \\ IMF International Monetary Fund \\ OWS Operation Warp Speed \\ R\&D Research and Development \\ SAM Social Accounting Matrix \\ UN United Nations \\ WHO World Health Organization \\ WTO World Trade Organization
}




\section{Acknowledgements}

The study team especially thanks the reviewers of this study, Charlene Rohr, Senior Research Leader at RAND Europe, and Jon Sussex, Chief Economist at RAND Europe. Their thoughtful comments helped to sharpen our analysis and pointed us to improvements in our thinking. Erez Yerushalmi is Senior Lecturer at Birmingham City University and RAND Europe affiliate. The authors of course assume full responsibility for the study's findings. The quality of the prose has benefited enormously from the careful copy-editing of Ben Plumridge. 



\section{Introduction}

COVID-19, caused by severe acute respiratory syndrome coronavirus 2 (SARS-CoV-2), emerged publicly in late December 2019 in the Chinese province of Wuhan and has since then rapidly spread to other countries in Asia, Europe, North America and the rest of the world. The World Health Organization (WHO) declared a global pandemic on 11 March 2020 and almost every country has reported cases of individuals infected with the virus (Cookson 2020). As of September 2020, the total number of confirmed cases globally is more than 30 million, with over 1 million deaths, and the number of infections is rising steadily across much of the globe as winter approaches (Roser et al. 2020). As well as the associated health burden, the COVID-19 outbreak has caused substantial damage to the global economy, with the International Monetary Fund (IMF) and World Bank predicting a deeper global recession than the one that occurred in 2008/9 (Gopinath 2020).

Until there is a vaccine or other treatment widely available, physical distancing, the use of face masks and test, track and tracing will most likely be the only effective measures in the battle against the spread of the disease. There is an unprecedented global research effort ongoing to find a vaccine against SARS-CoV-2. Currently there are more than 165 vaccines being developed, with some already in human trials. While the current efforts to develop a safe and effective vaccine for SARS-CoV-2 are being conducted at an unprecedented speed, further decision and investment challenges for policymakers will emerge with regard to the manufacturing and distribution of such a vaccine once it becomes available.

At the beginning of the pandemic, three basic scenarios were plausible in terms of the development, manufacturing and distribution of vaccine candidates (Bremmer 2020). Firstly, upon the discovery and development of a safe and effective vaccine, governments and international organisations could work closely together to coordinate globally its manufacturing and distribution and guarantee equitable access across countries. Secondly, as countries develop a vaccine, their populations would get first access to it based on their initial investments; once these countries have immunised their populations sufficiently, they would then help international institutions such as the $\mathrm{WHO}$ and the $\mathrm{UN}$ in the distribution and uptake of the vaccine in all other countries which may have missed out initially. Thirdly, countries could take a 'my nation first' approach, where each country solely protects its own interest and competes against others for the initially limited supply of vaccines. 
Currently, the approach to vaccine development sits somewhere between the second and third scenario and is most commonly characterised as 'vaccine nationalism'. A lack of global coordination and cooperation could have negative consequences on how well the global pandemic is managed and contained. As international institutions like the WHO and the UN continuously point out, a global crisis like the COVID-19 outbreak needs a globally coordinated response and COVID-19 vaccines should be treated as global public goods (Lee \& Yang 2020). But while international institutions such as the UN, WHO and the Global Alliance for Vaccines and Immunization (GAVI), among others, are trying to support the multilateral option to globally coordinate the COVID-19 vaccine effort, the United States and other countries have been reluctant to commit and instead pursued a strategy of signing deals directly with pharmaceutical companies to gain first access to a supply of vaccines (Milne \& Crow 2020).

\subsection{Objectives}

This study examines some of the potential consequences associated with 'vaccine nationalism' and has two main objectives. Firstly, it aims to identify and discuss some of the implications of the currently observed nationalistic behaviour of many countries for how the global crisis is managed and contained should potential vaccine candidates emerge that are safe and show the desired immune response. Secondly, the study aims to quantify the potential economic effects associated with non-equitable access to vaccines across different countries.

As already experienced, there will inevitably be calls for nationalism in relation to the allocation of potential coronavirus vaccines, and national governments will feel pressure to put their own citizens first. But in a global pandemic, simply shielding one's own citizens will most likely lead to others being left behind, resulting in the inefficient allocation of available vaccines (potentially treating individuals less at risk in a high-income country before high-risk individuals in a poor country). However, as long as the virus is not under control in all regions of the world, global economic demand will most likely still be impaired and global supply chains interrupted. Due to physical distancing measures and regulations, even in the absence of wide-ranging containment and closure measures it will be highly contact-intensive sectors ${ }^{1}$ such as travel, tourism, transportation, hospitality and entertainment which will continue to be heavily affected in the absence of an effective vaccine for COVID-19 (Famiglietti et al. 2020).

A better understanding of the economic consequences of inequitable access to a vaccine is absent in the wider public debate and this study aims to bridge this gap. It is important to highlight that we focus on the inequitable access of potential COVID-19 vaccines between countries and regions, for example between wealthier and poorer countries; we do not consider the most efficient and equitable distribution of vaccines within countries or regions.

\subsection{Methodological approach}

The study draws on a set of different research methods. Firstly, we have conducted a literature review to gain a better understanding of some of the risks and problems associated with 'vaccine 
nationalism'. Secondly, we have applied a macroeconomic modelling framework to assess the economic implications of inequitable access to a vaccine under different scenarios.

Given that many countries have already eased some of their strict quarantine and containment measures, we aim to model the post-lockdown and pre-vaccine world where the virus is not fully contained worldwide causing further slack in global economic production across many sectors, particularly those that are highly contact-intensive such as travel, transportation, tourism, hospitality and entertainment, and hence especially negatively impacted by physical distancing measures and regulations. In this study, we examine the COVID-19 induced impact on global Gross Domestic Product (GDP) of reduced economic activity in these highly contact-intensive service sectors. The continuing negative impact in contact-intensive sectors also indirectly affects other sectors in the economy as they serve as intermediate inputs into other industries such as agriculture and manufacturing. For instance, transportation services are a very important input to many production processes. Such linkages between contact-intensive and less contactintensive sectors have ripple effects through the whole economy. Furthermore, service sectors such as hospitality, recreation and entertainment are not only important for a country's domestic economy but also represent tourism-related service trade between countries.

\subsection{The structure of this report}

The remainder of this report is structured as follows. Chapter 2 examines some of the factors in vaccine development and allocation that put global equitable access to vaccines at risk. Chapter 3 analyses some of the economic costs associated with vaccine nationalism. Chapter 4 outlines the conclusions of the report and discusses recommendations. In Appendix A we provide a more detailed description of the economic model. Appendix B provides additional findings of the economic analysis. 



\section{Background: the COVID-19 crisis and a lack of global coordination and cooperation}

As long as there are ongoing outbreaks of the virus around the world, individuals will still get ill and have to stay off work, schools may have to close again, and travel, tourism, commerce, education and other contact-intensive sectors will most likely not recover to pre-pandemic levels. For that reason, every country is keen to find a way out of the global COVID-19 pandemic in order to reduce the strain on health systems, protect citizens from illness and death and minimise the economic damage from additional containment and closure measures. For many governments a vaccine against SARS-CoV-2 appears to be the best solution.

The race to develop a vaccine against SARS-CoV-2 is well underway and initial testing across different potential vaccine candidates appears promising (Cookson \& Gross 2020). The goal of a vaccine is to raise an immune response so that when a vaccinated person is exposed to the virus their immune system will take care of the pathogen and the individual will not get infected. Should a vaccine be proven safe and effective, vaccinating large parts of the population would reduce the number of suspectable individuals, ideally below a threshold where the virus will no further spread. There is much uncertainty about whether it will be feasible to develop a vaccine where the vast majority of the population will be immunised for life, or whether the COVID-19 vaccine will be more like those that protect from seasonal influenza, requiring renewal over time (Gross 2020). There are currently more than 165 coronavirus vaccines in development, and some of them already in clinical trials (Corum et al. 2020). Some best-case estimates predict that a safe and effective vaccine could be available by the end of 2020 or early 2021, with the ambitious 12-18 month timeline unprecedented in the development of a vaccine (Crow 2020; Hanney et al. 2020). Several organisations are working on a vaccine in public-private partnerships, such as that between the University of Oxford and the pharmaceutical company AstraZeneca (University of Oxford 2020), relying on initial funding from government or private donors. Because it is difficult to assess in the early stages of development which vaccines will be safe and effective, it is important to conduct multiple development efforts in parallel to ensure the timely availability of a vaccine (Yamey et al. 2020).

While the development of a vaccine is central to global efforts to restart economies, a big question is whether countries will act in their narrow self-interest or embrace a more collaborative, global, multilateral approach towards developing, manufacturing and distributing the vaccine. So far it has been mostly national self-interest that has characterised the dealings of many governments since the onset of the pandemic. Increasingly the view is that public health is a national security issue and therefore national governments see the availability of a 
vaccine for its own population as a priority. Fear of not having enough medical supplies has led governments to enact both export restrictions and import liberalising measures for crucial medical supplies as well as personal protective equipment (Evenett 2020). While these imposed restrictions may have boosted the domestic supply of medical equipment, they have shifted the negative implications of supply shortages on to other countries; and as the number of countries implementing such restrictions has escalated, the risk is spiralling protectionism that could leave everyone worse off (Gertz 2020). Experience from the 2009 H1N1 pandemic suggests that when faced with a global public health problem, wealthier countries tend to push to get first access to a supply of vaccines by signing deals directly with pharmaceutical companies and hoard key vaccine supplies, a situation commonly referred to as 'vaccine nationalism' (Milne \& Crow 2020).

In what follows we examine in more detail some of the implications of 'vaccine nationalism' for the process of developing and producing vaccines, as well as its potential consequences in terms of equitable access to vaccine candidates across countries.

\subsection{The global ('arms') race to deliver vaccines could harm public trust}

The race for a vaccine is deeply intertwined with the current geopolitical situation. The US and China see the discovery of a vaccine as illustrative of their superiority. Russia has also entered the public race to be first and has announced it could start widespread community vaccination with its 'Sputnik-V' vaccine as early as fall 2020 (despite showing a desired immune response, there is some scepticism among international experts about the potential safety and effectiveness of Russia's 'Sputnik V' vaccine so far; Kramer 2020). The showcased rivalry between the global superpowers could complicate a globally coordinated approach to find a solution to the current COVID-19 crisis. Moreover, the pandemic has happened in an era of decreasing multilateralism and rising tensions between the world's superpowers (Grossman 2019). The country that rolls out the first vaccine may use it to promote 'vaccine diplomacy' and potentially reward geopolitical allies (Johnson \& Dou 2020). China, for example, has a handful of potential COVID-19 vaccines in the race and China's official aim to be one of the first to have a vaccine is not only a matter of national pride but also a way to demonstrate superiority (Milne \& Crow 2020). The US administration under President Trump has also previously declared it will be one of the first countries to produce a vaccine to immunise the US population and it has been considering bypassing normal US regulatory standard approvals to fast track a potential vaccine currently developed in the UK for use in the US before the presidential elections (Kuchler, Crow et al. 2020).

The geopolitical competition regarding COVID-19 vaccine candidates could induce countries to speed up their trials and, to satisfy public demand, push for quicker and riskier regulatory approvals. If an unproven vaccine is mass distributed in many regions, or distributed without sufficient approvals, and it turns out that it is not effective or has severe side-effects, this could further erode public trust in vaccines, which are already unpopular in some parts of the population. This would make rolling out national immunisation even harder (Yaqub et al. 2014; Badur et al. 2020). 


\subsection{Nationalistic behaviour could negatively affect global vaccine supply chains}

Much public attention is focused on the scientific race to create a vaccine. But efforts are also being made in developing the global vaccine supply chain - what experts have referred to as the 'biggest logistical challenge the world has ever faced' (Steenhuysen \& Kelland 2020). Vaccine manufacturing is a complex and expensive process and the infrastructure needed will depend on the type of the vaccine.

Producing a vaccine involves several different manufacturing steps. Typically, this might include: (1) the purification of raw ingredients; (2) the formulation and addition of stabilisers, preservatives and adjuvants; (3) the packaging of the doses into vials or syringes. Only a few dozen companies globally, most of them based in the US, the EU, the UK, and some in China and India, can carry out the last step and even fewer can handle the quality-controlled manufacturing of active ingredients, which is especially important for novel and more sophisticated vaccines (Mancini et al. 2020). For those companies currently developing a vaccine there are a lot of steps in the process from development to production and distribution to consider. A vast amount of input materials needs to be available to initiate the production process, with demand substantially greater than experienced before as virtually every individual globally will need one or several doses. Furthermore, there is also the challenge that poorer countries may not have adequate systems to deliver and administer the vaccines (Kirby 2020).

Another difficulty is that the supply chains for vaccine production are global. Any country wanting to manufacture a vaccine is unlikely to possess all the inputs necessary to scale up and sustain production. Components for a vaccine usually come from different geographical locations and often different countries specialise in a specific stage of the production process. This could enable some countries that are not able to manufacture a vaccine themselves, but which have control of the supply of important inputs to ensure their access to finished products. However, if these countries instead choose to hoard some of the inputs, the global vaccine supply chains could become interrupted, causing delays in production and eventually denying some countries access altogether (Bollyky \& Bown 2020).

\subsection{International competition for vaccine supplies could negatively affect global affordability}

Many governments have signed direct deals with producers of potential COVID-19 vaccines in order to secure a stock for their populations. For instance, at the time of writing the UK has signed an agreement with the pharmaceutical companies alliance BioNtech/Pfizer as well as deals with AstraZeneca, Valneva and GSK/Sanofi (Miller \& Cookson 2020; Abboud 2020). The US has established Operation Warp Speed (OWS), a partnership between the Department of Health and Human Services, the Department of Defense and a wider set of health-related agencies. The goal of OWS is to deliver 300 million doses of a vaccine by January 2021. OWS also aims to buy medicines known as antibody therapies and is part of a broader government strategy to accelerate the procurement of drugs and diagnostic tests. As part of this effort, the US government triggered international outrage at the end of June 2020 when it bought up most of the supply of the drug Remdesivir that the drug firm Gilead had for the next quarter. In addition 
the US has signed direct vaccine deals with BioNtech/Pfizer and Moderna (Kuchler 2020; Miller \& Cookson 2020). At least four European countries - Germany, France, Italy and the Netherlands have also signed direct deals with AstraZeneca (Reuters 2020) and some governments such as the UK and the US have made funding conditional on providing their domestic populations with a vaccine first.

As international institutions such as the $\mathrm{WHO}$ and the UN point out, a global crisis needs a globally coordinated response and COVID-19 vaccines should be treated as global public goods (Lee \& Yang 2020). There have been international efforts to coordinate the development, production and distribution of potential vaccine candidates. For instance, the WHO Access to COVID Tools (ACT) Accelerator is a global initiative to accelerate the development and production of COVID-19 tests, treatments and vaccines and ensure equitable access to them (WHO 2020a). Investment pledges were launched at the end of June 2020 with a call for \$31.3bn funding, but at the time of writing a large gap remains in the funds pledged (Ellyatt 2020). The ACT Accelerator vaccine pillar, named the COVAX Facility, is coordinated by the Coalition for Epidemic Preparedness Innovations (CEPI) and GAVI, and offers a model to pool vaccine procurement. The idea is that by pooling resources, the facility can invest in multiple vaccine candidates and provide manufacturers with the volume guarantees for specific vaccine candidates before they can be licensed. The secured doses will then be shared equally between all participating countries, proportionately to the size of their populations (WHO 2020b). With regard to financing, higher-income countries would self-finance their share of the vaccine through their public budgets and will be required to provide an upfront payment and a binding commitment to buy the doses from the facility, whereas lower-income countries would be supported by the GAVI Advance Market Commitment. ${ }^{2}$ However, the facility has so far struggled to convince some highincome countries such as the US which have instead pursued direct bilateral deals with vaccine manufacturers (Mancini \& Peel 2020). Some wealthier countries have joined COVAX and committed to contribute financially but declared most likely not to procure their vaccines through the facility (Cheng \& Hinnant 2020).

The large number of bilateral deals between national governments and producers of current vaccine candidates has resulted in a patchwork of agreements which could affect pricing of potential vaccines as wealthier countries bid for limited vaccine supplies, and eventually price out or deny, at least initially, governments of less wealthy countries access to some vaccine candidates. For instance, some argue that the large number of bilateral deals between wealthier countries and vaccine producers could mean that more than 60 per cent of the world population would not have access to a vaccine until at least 2022 (Balfour 2020). While bilateral deals between wealthier countries and producers of vaccines can have a positive effect on the R\&D process, they also hinder global cooperation on how to make the best vaccine candidates quickly and efficiently available globally for those people most at risk. Many of the current agreements do not disclose the agreed prices but for those that do, the variation is large. For instance, the US deal for the BioNtech/Pfizer agreement is set at $\$ 19.50$ per dose, which is higher than estimates for an AstraZeneca supply agreement with the four EU countries (\$3 to \$4 per dose). Moderna is pitching its potential vaccine at $\$ 25$ to $\$ 30$ per dose (Kuchler, Cookson et al. 2020). Ultimately, 
by not investing in facilities such as COVAX, countries that have focused on specific vaccine candidates and not a larger pool could lose out, if they have exclusively bet on vaccine candidates that fail during the development process.

\subsection{Implications}

Without a safe, effective and globally accessible vaccine, COVID-19 will continue to threaten lives and livelihoods. The pandemic is global and virtually all parts of the world are experiencing a significant number of cases among their populations. A lack of global coordination with regard to the development, production and distribution of potential COVID-19 vaccine candidates could have negative consequences on the price and quality of potential vaccines and is likely to hamper equitable access for people at most risk across the globe, with poorer countries' access most likely hit the hardest. In the worst-case scenario a 'my nation first' approach will see vaccine doses allocated to moderately at-risk individuals (e.g. the younger population in the US), while populations at higher risk in poorer countries lose out. As long as the virus is not under control in all regions of the world, global economic demand will remain below pre-pandemic levels, with individuals continuing to get ill and miss days at work or school, and contact-intensive sectors such as tourism and travel that are highly reliant on close personal interactions substantially affected. In contrast, global cooperation and equitable vaccine allocation could allow economies all around the globe to come gradually back on track, avoiding supply chain disruptions and perhaps even preventing unnecessary geopolitical conflicts.

It appears that countries are currently trapped in what resembles the classic game theory problem known as 'the prisoner's dilemma': two completely rational individuals (e.g. two prisoners) might not cooperate even if it is evident to a third party outside the game that it would be in their best interests to do so (e.g. a lower prison sentence). This outcome is manifested because betraying a partner appears to offer a greater reward than cooperating with them and all purely rational prisoners would betray the other if they cannot trust each other (Farnam Street 2020). In the current real-world situation, many governments feel that they cannot rely on other countries, even close allies, when it comes to this global public health crisis. Even individual countries within the EU closed their borders and hoarded their domestic supplies of medical equipment (Cookson et al. 2020). For many political leaders the time horizon is also short and some are working towards imminent re-election. For these politicians, providing a vaccine to their own population first seems to be a dominant strategy compared with supporting a more global cooperative approach, even though it could have longer-term negative economic consequences. One important factor is that the development and allocation of a COVID-19 vaccine will most likely not be a one-shot situation. Multiple vaccines may emerge in the future, each with different benefits or strengths, and future populations will likely also need to be vaccinated if the virus does not disappear. Some of them may be more suitable for different segments of the population (e.g. children or the elderly). The vaccines currently in development also use different ingredients and inputs distributed through global supply chains, which gives some countries negotiation power. Thus, if one country does indeed withhold access to an early vaccine, those other countries might retaliate by withholding a more effective vaccine later on (Bollyky \& Bown 2020). 



\section{Estimating the economic 3 implications of vaccine nationalism}

One of the main sources of economic impact associated with the COVID-19 pandemic has been the change in the behaviour of households and firms and the closure of many non-essential sectors to curb the transmission of the virus. Some firms have been able to implement remote working arrangements using new technologies, but others that require their workers to be physically present at a specific work location have suffered particularly during the pandemic. The response of households has been driven by the fear of containing the virus as well as by the inability to undertake certain economic activities. Even as many countries are in the process of easing the stringent quarantine and containment measures that were introduced during the first months of the pandemic, and until there is a vaccine widely available, many economic sectors, especially those relying on close physical interaction, will most likely continue to be adversely affected. This is driven by prolonged physical distancing measures and regulations, although individuals also continue voluntarily to be cautious in their actions and they may generally spend less due to uncertain economic times. ${ }^{3}$ As discussed in the previous chapter, if many countries follow a 'my nation first' approach, this could have direct negative implications for the vaccine access of other countries and could potentially deny access to a vaccine for some countries altogether, at least initially. In this chapter we aim to quantify the potential economic implications if only a few countries have access to COVID-19 vaccines.

Our approach for estimating the potential macroeconomic implications of inequitable access to vaccines associated with 'vaccine nationalism' centres on the COVID-19-induced effects of prolonged reduced economic activity in highly contact-intensive sectors. For the analysis, we have used a global macroeconomic model where all countries in the world are interlinked with each other through trade in goods and services as well as investment. The model allows us to put the world economy into a laboratory and run different 'what-if' experiments - in other words to see what would happen to global economic output (measured through GDP) if no vaccine was developed or only a few countries or regions managed to inoculate their own populations. 
In what follows we describe in more detail the macroeconomic model and the simulated 'whatif' scenarios, and then present the empirical results. More technical details about the modelling approach can be found in Appendix A.

\subsection{Modelling approach}

We used a multi-country, multi-sector computable general equilibrium (CGE) model to quantify the potential global economic situation in a post-lockdown pre-vaccine COVID-19 world and then to assess the economic implications of inequitable access to COVID-19 vaccines between countries or global regions. The model represents the full economy of a given country or region. As discussed by Lofgren et al. (2002), a CGE model is essentially a large numerical macroeconomic model that combines economic theory with real economic data in order to derive the economic impacts of events in an economy. Our core model resembles that of Lanz \& Rutherford (2016).

CGE models arrive at their outputs by capturing the behaviour of different economic agents in the economy, including (1) firms; (2) consumers; (3) government; and (4) foreign agents. Firms seek to combine factor inputs such as capital and labour to maximise profits; consumers allocate their disposable income between savings and consumption to maximise their welfare; the government levies and collects taxes, distributes social benefits but also purchases goods; and foreign agents interact with domestic agents through international trade and international factor flows (e.g. migration, foreign direct investment). The behaviour of each of the agents is based on economic theory and specified mathematically as a system of equations that is solved simultaneously to obtain a situation in which all markets are cleared (i.e. supply equals demand), which is called an 'equilibrium'. The model includes different production sectors and goods markets and it also has a government budget constraint that allows it to capture government expenditure in different sectors. In the model, government expenditure is financed through the collection of taxes from firms and households and from import duties. In addition, all economic interactions in the model also involve foreign agents that exchange goods and services with domestic agents through international trade.

In the model, events are evaluated as 'shocks' to the economic system. The initial baseline solution reflects a scenario that represents the state of a country's economy in the absence of a specific shock. Then the model is 'shocked' to reflect the new state of the world (e.g. the outbreak of a global pandemic) and the new equilibrium represents a 'what-if' scenario. The comparison between this scenario and the pre-shock baseline at any given point in time represents the impact of the event, for instance in terms of the effect on overall economic production (as measured through GDP). It is therefore important to highlight that the model does not provide a specific economic forecast of a country's economic growth at a specific point in time, but represents the difference in an indicator of interest (e.g. GDP) between different scenarios.

\subsubsection{Modelling the impact of reduced economic activity in contact-intensive sectors}

Until there is a widely available vaccine for COVID-19, or any other treatment, physical distancing regulations and measures and cautious human behaviour to avoid contracting the virus will most likely continue to affect key sectors negatively, especially those that rely on close physical 
interaction. As part of our economic analysis, we therefore model the impact on GDP of reduced activity induced by physical distancing and changes in consumer behaviour in five highly contactintensive service sectors: hospitality, recreation, retail and wholesale, transportation and health and social care. ${ }^{4}$

The hospitality and recreation sectors include establishments such as hotels, restaurants and bars. These sectors are not only important for the domestic economy but also include the tourism- and travel-related service trade which is exchanged between countries. While many countries have eased the stringent closure measures for this sector, empirical evidence suggests that many establishments are still running below their 'normal' capacity (Yu \& Xueqiao 2020). Strict regulations such as physical distancing measures mean that many restaurants and bars cannot reopen to previous capacity levels (for example because the number of tables per indoor space is regulated). Furthermore, the World Trade Organization (WTO) reports that tradable services that rely on physical proximity related to tourism, such as hospitality or recreation, have seen relatively strong increases in effective trade costs due to physical distancing and travel restrictions (WTO 2020).

Retail and wholesale refer to all operations around retail shops and wholesale, including car retail networks. During lockdown, online sales for many retailers have increased by displacing traditional personal in-store purchases in order to avoid close physical contact. In many countries, it is now mandatory to wear face masks to enter indoor retail establishments and the number of people that can be in a shop simultaneously is also commonly restricted, depending on national guidelines (McMorrow \& Eley 2020).

Transportation includes all modes of transport services for personal and cargo transport, including air, rail and water. It is a key service sector for economic activity and serves also as an intermediate input factor for many manufacturing sectors and other business services domestically as well as internationally. The transportation sector has experienced a sharp reduction, especially in passenger transport demand. This drop has been driven by a combination of government lockdown policies and the fear of contracting or transmitting the virus when using different modes of public transport. For freight transport, the impact is more complex, driven by different demand and supply factors and the need to keep essential services operating (Sung \& Monschauer 2020). The airline industry has been severely affected by border closures, quarantine measures and low demand; many analysts expect the airline sector to continue to be negatively impacted by the COVID-19 pandemic, with an increasing number of regulations that airlines and passengers will have to comply with in order to fly (Powley et al. 2020). Public transport has also been negatively affected: for instance, the lockdowns imposed in the UK in March 2020 led to a 95 per cent decrease in Underground rail journeys in the metropolitan region of London (Alfaro 2020).

Impacts on the health and social care sectors have also been significant. One of the reasons for very stringent containment measures is to ensure that health systems are able to cope with the

Appendix A provides more technical detail about the parameter assumptions taken and how the changes in reduced activity in the five contact-intensive sectors have been taken into account from a modelling perspective. In essence, the impact of reduced economic activity in the five highly contact-intensive sectors is modelled as a change in the relative price of the services produced in each specific sector. 
increased demand for services (while at the same time slowing the spread of the virus). However, there is evidence that during the pandemic people have avoided seeking healthcare for other health issues - even more severe health problems such as heart disease and cancer - due to fears of contracting the virus (Bernstein \& Sellers 2020; Neville et al. 2020). As a result of this aversion behaviour, the net effect with respect to the volume of supply and demand for healthcare is ambiguous.

While these five contact-intensive service sectors represent important pillars of domestic economic output in many countries, they are also of relative importance in the international trade of services and goods. For instance, the hospitality and recreation sectors are key to the tourismrelated service trade between countries. Furthermore, transportation represents a key input to many manufacturing sectors, domestically as well as internationally. Therefore, changes in demand or supply in these sectors can have indirect consequences for international trade costs. The lower quantity of passenger flights, for instance, has an indirect negative effect on air cargo prices because of the lack of cargo-belly capacity in passenger planes and hence the negative impact on the transportation sector has indirectly negative effects on international trade as transportation is an important intermediate input along value chains. ${ }^{5}$

\subsubsection{Data sources}

\section{Global Trade Analysis Project database for underlying economic data}

The underlying economic data used for the purpose of our analyses are taken from the Global Trade Analysis Project (GTAP) database. This database has been developed and continuously updated by the Centre for Global Trade Analysis at Purdue University since 1993. Overall, GTAP covers 140 countries and 57 GTAP commodities, and includes all bilateral trade patterns, production, consumption and intermediate inputs of commodities and services. For the purpose of this analysis we have aggregated the 140 countries into 9 regions (Table 3.1) and the 57 GTAP commodities into 8 broader sectors (Table 3.2). 
Table 3.1. Countries and regions included in the analysis

\begin{tabular}{|c|c|}
\hline Country/region & Countries \\
\hline USA & United States \\
\hline UK & United Kingdom \\
\hline $\mathrm{EU}-27$ & $\begin{array}{l}\text { Austria, Belgium, Bulgaria, Croatia, Cyprus, Czech Republic, } \\
\text { Denmark, Estonia, Finland, France, Germany, Greece, Hungary, } \\
\text { Ireland, Italy, Latvia, Lithuania, Luxembourg, Malta, Netherlands, } \\
\text { Poland, Portugal, Romania, Slovakia, Slovenia, Spain, Sweden }\end{array}$ \\
\hline China & China \\
\hline Russia & Russia \\
\hline India & India \\
\hline High income & $\begin{array}{l}\text { Australia, New Zealand, Rest of Oceania, Hong Kong, Japan, Korea, } \\
\text { Taiwan, Brunei Darussalam, Indonesia, Malaysia, Singapore, Canada, } \\
\text { Mexico, Brazil, Chile, Colombia, Uruguay, Costa Rica, Panama, } \\
\text { Puerto Rico, Trinidad and Tobago, Switzerland, Liechtenstein, } \\
\text { Iceland, Norway, Bahrain, Israel, Kuwait, Oman, Qatar, Saudi Arabia, } \\
\text { Turkey, United Arab Emirates, Mauritius, South Africa }\end{array}$ \\
\hline Middle income & $\begin{array}{l}\text { Thailand, Argentina, Ecuador, Paraguay, Peru, Venezuela, Guatemala, } \\
\text { Dominican Republic, Jamaica, Caribbean, Albania, Belarus, Ukraine, } \\
\text { Moldavia, Bosnia and Herzegovina, Macedonia, Montenegro, Serbia, } \\
\text { Kazakhstan, Armenia, Azerbaijan, Georgia, Iran, Jordan, Botswana, } \\
\text { Namibia. }\end{array}$ \\
\hline Low income & $\begin{array}{l}\text { Mongolia, North Korea, Cambodia, Lao People's Democratic } \\
\text { Republic, Philippines, Viet Nam, Myanmar, Timor-Leste, Bangladesh, } \\
\text { Nepal, Pakistan, Sri Lanka, Afghanistan, Bhutan, Bolivia, Guyana, } \\
\text { Suriname, Honduras, Nicaragua, El Salvador, Belize, Kyrgyzstan, } \\
\text { Tajikistan, Turkmenistan, Uzbekistan, Iraq, Lebanon, Yemen, } \\
\text { Syria, Egypt, Morocco, Tunisia, Algeria, Libya, Benin, Burkina Faso, } \\
\text { Cameroon, Cote d'Ivoire, Ghana, Guinea, Nigeria, Senegal, Togo, } \\
\text { Cape Verde, Gambia, Guinea-Bissau, Liberia, Mali, Mauritania, Niger, } \\
\text { Sierra Leone, Central African Republic, Chad, Congo, Equatorial } \\
\text { Guinea, Gabon, Angola, Democratic Republic of Congo, Ethiopia, } \\
\text { Kenya, Madagascar, Malawi, Mozambique, Rwanda, Tanzania, } \\
\text { Uganda, Zambia, Zimbabwe, Burundi, Djibouti, Eritrea, Somalia, } \\
\text { Sudan, Lesotho, Swaziland }\end{array}$ \\
\hline
\end{tabular}

Source: Based on GTAP 10a. 
Table 3.2. Sectors included in the analysis

\begin{tabular}{|l|l|}
\hline Sector & Description \\
\hline Agriculture \& manufacturing & Agriculture, manufacturing \\
\hline Hospitality & Accommodation, food \\
\hline Recreation & Recreation \\
\hline Retail and wholesale & Retail and wholesale distribution \\
\hline Transportation & Air travel, water and other transport \\
\hline Health and social care & Human health and social work \\
\hline Education & Education \\
\hline Other services & $\begin{array}{l}\text { Construction, warehousing, communication, financial services, } \\
\text { insurance, real estate, business services, public administration, dwellings }\end{array}$ \\
\hline
\end{tabular}

Source: Based on GTAP 10a.

\section{A mix of data to model changes in sectorial economic activity}

In order to get a sense of magnitude on the extent to which contact-intensive sectors are likely to continue to be negatively affected in a post-lockdown and pre-vaccine economy, we draw on a set of different data sources. ${ }^{6}$

Firstly, we use data on sector-specific production values since the outbreak of the global COVID19 pandemic. ${ }^{7}$ Sweden has had a relatively less stringent set of containment and closure policies than many other countries. Hence, using Swedish sectorial data provides a useful benchmark on how economic activity in some of the contact-intensive sectors is affected, even in the absence of strict closure and containment measures. As our base case value $(M)$ assumption, we use 50 per cent of the average year-on-year changes in the production value by service sector from March to August 2020. In order to add sensitivity, we vary the value assumption: as lower value $(L)$ we use 25 per cent and as the higher value $(H)$ we use 75 per cent of the average year-on-year change in the production value by sector from March to August 2020.

Secondly, we draw on community mobility data provided by Google (2020) to obtain a proxy benchmark on how activity in the contact-intensive sectors may vary by country or region compared to Sweden. That is, assuming that changes in mobility to locations such as retail and recreation, groceries and pharmacies, parks, transit stations, workplaces or residential are correlated with changes in economic activity, ${ }^{8}$ we calculate a country- or region-specific adjustment factor which we apply to the assumed benchmark changes in sectorial activity data from Sweden. More technical details about the assumptions regarding the changes in economic activity by contact-intensive sector and country or region is provided in Appendix A. Table 3.3 summarises the assumptions by sector and country or region.

6 Appendix A provides more detail about the data and the assumptions made.

$7 \quad$ We employed information based on monthly and seasonally adjusted Swedish production value data (Statistics Sweden 2020). 
Table 3.3. Assumed country- or region-specific changes in economic activity by contact-intensive sector

\begin{tabular}{|c|c|c|c|c|c|}
\hline & Hospitality & Recreation & $\begin{array}{l}\text { Retail and } \\
\text { wholesale }\end{array}$ & Transportation & $\begin{array}{l}\text { Health and } \\
\text { social care }\end{array}$ \\
\hline \multicolumn{6}{|c|}{ M: Base case assumption } \\
\hline USA & $-18.5 \%$ & $-6.5 \%$ & $-3.4 \%$ & $-9.4 \%$ & $-2.9 \%$ \\
\hline UK & $-18.3 \%$ & $-6.5 \%$ & $-3.4 \%$ & $-9.3 \%$ & $-2.9 \%$ \\
\hline China & $-16.2 \%$ & $-5.7 \%$ & $-3.0 \%$ & $-8.2 \%$ & $-2.6 \%$ \\
\hline EU-27 & $-16.4 \%$ & $-5.8 \%$ & $-3.0 \%$ & $-8.3 \%$ & $-2.6 \%$ \\
\hline High & $-18.1 \%$ & $-6.4 \%$ & $-3.3 \%$ & $-9.2 \%$ & $-2.9 \%$ \\
\hline India & $-16.7 \%$ & $-5.9 \%$ & $-3.1 \%$ & $-8.5 \%$ & $-2.7 \%$ \\
\hline Russia & $-16.2 \%$ & $-5.7 \%$ & $-3.0 \%$ & $-8.2 \%$ & $-2.6 \%$ \\
\hline Medium & $-18.2 \%$ & $-6.4 \%$ & $-3.4 \%$ & $-9.2 \%$ & $-2.9 \%$ \\
\hline Low & $-17.3 \%$ & $-6.1 \%$ & $-3.2 \%$ & $-8.8 \%$ & $-2.7 \%$ \\
\hline \multicolumn{6}{|c|}{ L: Lower value assumption } \\
\hline USA & $-9.3 \%$ & $-3.3 \%$ & $-1.7 \%$ & $-4.7 \%$ & $-1.5 \%$ \\
\hline UK & $-9.2 \%$ & $-3.2 \%$ & $-1.7 \%$ & $-4.6 \%$ & $-1.5 \%$ \\
\hline China & $-8.1 \%$ & $-2.9 \%$ & $-1.5 \%$ & $-4.1 \%$ & $-1.3 \%$ \\
\hline EU-27 & $-8.2 \%$ & $-2.9 \%$ & $-1.5 \%$ & $-4.2 \%$ & $-1.3 \%$ \\
\hline High & $-9.1 \%$ & $-3.2 \%$ & $-1.7 \%$ & $-4.6 \%$ & $-1.4 \%$ \\
\hline India & $-8.4 \%$ & $-3.0 \%$ & $-1.5 \%$ & $-4.2 \%$ & $-1.3 \%$ \\
\hline Russia & $-8.1 \%$ & $-2.9 \%$ & $-1.5 \%$ & $-4.1 \%$ & $-1.3 \%$ \\
\hline Medium & $-9.1 \%$ & $-3.2 \%$ & $-1.7 \%$ & $-4.6 \%$ & $-1.4 \%$ \\
\hline Low & $-8.6 \%$ & $-3.1 \%$ & $-1.6 \%$ & $-4.4 \%$ & $-1.4 \%$ \\
\hline \multicolumn{6}{|c|}{$\mathrm{H}$ : Higher value assumption } \\
\hline USA & $-27.8 \%$ & $-9.8 \%$ & $-5.1 \%$ & $-14.1 \%$ & $-4.4 \%$ \\
\hline UK & $-27.5 \%$ & $-9.7 \%$ & $-5.1 \%$ & $-13.9 \%$ & $-4.4 \%$ \\
\hline China & $-24.3 \%$ & $-8.6 \%$ & $-4.5 \%$ & $-12.3 \%$ & $-3.9 \%$ \\
\hline EU-27 & $-24.6 \%$ & $-8.7 \%$ & $-4.5 \%$ & $-12.5 \%$ & $-3.9 \%$ \\
\hline High & $-27.2 \%$ & $-9.6 \%$ & $-5.0 \%$ & $-13.8 \%$ & $-4.3 \%$ \\
\hline India & $-25.1 \%$ & $-8.9 \%$ & $-4.6 \%$ & $-12.7 \%$ & $-4.0 \%$ \\
\hline Russia & $-24.3 \%$ & $-8.6 \%$ & $-4.5 \%$ & $-12.3 \%$ & $-3.9 \%$ \\
\hline Medium & $-27.3 \%$ & $-9.6 \%$ & $-5.0 \%$ & $-13.9 \%$ & $-4.3 \%$ \\
\hline Low & $-25.9 \%$ & $-9.2 \%$ & $-4.8 \%$ & $-13.2 \%$ & $-4.1 \%$ \\
\hline
\end{tabular}

Note: entries report assumed changes in economic activity by country or region and by contact-intensive sector. Details on assumptions are provided in Appendix A. 'M', 'L' and ' $H$ ' represent base case, lower and higher value parameter assumptions. 


\subsubsection{Other factors not directly included in the modelling exercise}

It is important to highlight that beyond the changes in economic activity in specific contactintensive sectors, other types of shocks could be equally important in determining potential COVID-19-induced economic effects. In addition to sector-specific supply- and demand-shocks, other studies have applied changes to the labour supply or effective trade costs (Maliszewska et al. 2020; McKibbin \& Fernando 2020). For instance, with no safe and effective vaccine, many people will still get infected with COVID-19, leading to increased levels of mortality and morbidity. Morbidity is very relevant from a macroeconomic perspective if it has negative consequences for the effective labour supply in an economy. ${ }^{9}$ However, as it is relatively difficult to predict how many people will get infected with COVID-19 from now until a potential vaccine is available, even with a very sophisticated epidemiological model at hand, we do not model the potential effects on the effective labour supply.

Other studies have also modelled a negative productivity shock when workers work remotely, although the evidence on home working is ambiguous. While some studies suggest that working from home could actually improve productivity under certain circumstances (Bloom et al. 2015), there is also a debate on whether that would apply during a global pandemic like COVID-19 (Gorlick 2020). We do not model the effect on the labour supply of changes in worker productivity and hence our estimates may represent a lower-bound value for the true magnitude of the effects.

Furthermore, some previous studies have also modelled an increase in bilateral trade costs, driven by additional inspections, reduced hours of operation, road and border closures, and increases in transportation costs (Maliszewska et al. 2020). However, it is generally difficult to quantify the direct effects of these factors on effective trade costs. Previous studies have assumed some broad changes in trade cost (e.g. a 25 per cent increase in the case of Ebola outbreaks between African countries). It is also difficult to predict what borders will be temporarily closed in the future until the global pandemic has been managed. There is currently a lot of variation in travel restrictions and often new quarantine rules are imposed at very short notice (Wright 2020). Hence, we do not model explicitly the effects of potentially higher effective trade costs. However, as we assume lower demand in transportation and other sectors that represent a relatively large share in the intermediate input to other sectors in foreign countries, we implicitly take some of the changes in trade costs into account. For instance, if transportation becomes more expensive, this has negative implications for the costs of intermediate inputs into production and therefore could indirectly affect prices of other goods produced in other sectors.

By not including the effects on labour supply or direct changes to effective trade costs, this analysis estimates the lower bound of the potential economic cost associated with the presence of COVID-19 in the absence of strict containment and closure measures in a pre-vaccine world. 


\subsection{The modelling scenarios}

We ran four main scenarios, each of which differs regarding the assumptions about which countries will have access to a COVID-19 vaccine and manage to sufficiently inoculate their population. Table 3.4 summarises the scenarios.

Table 3.4. The modelling scenarios

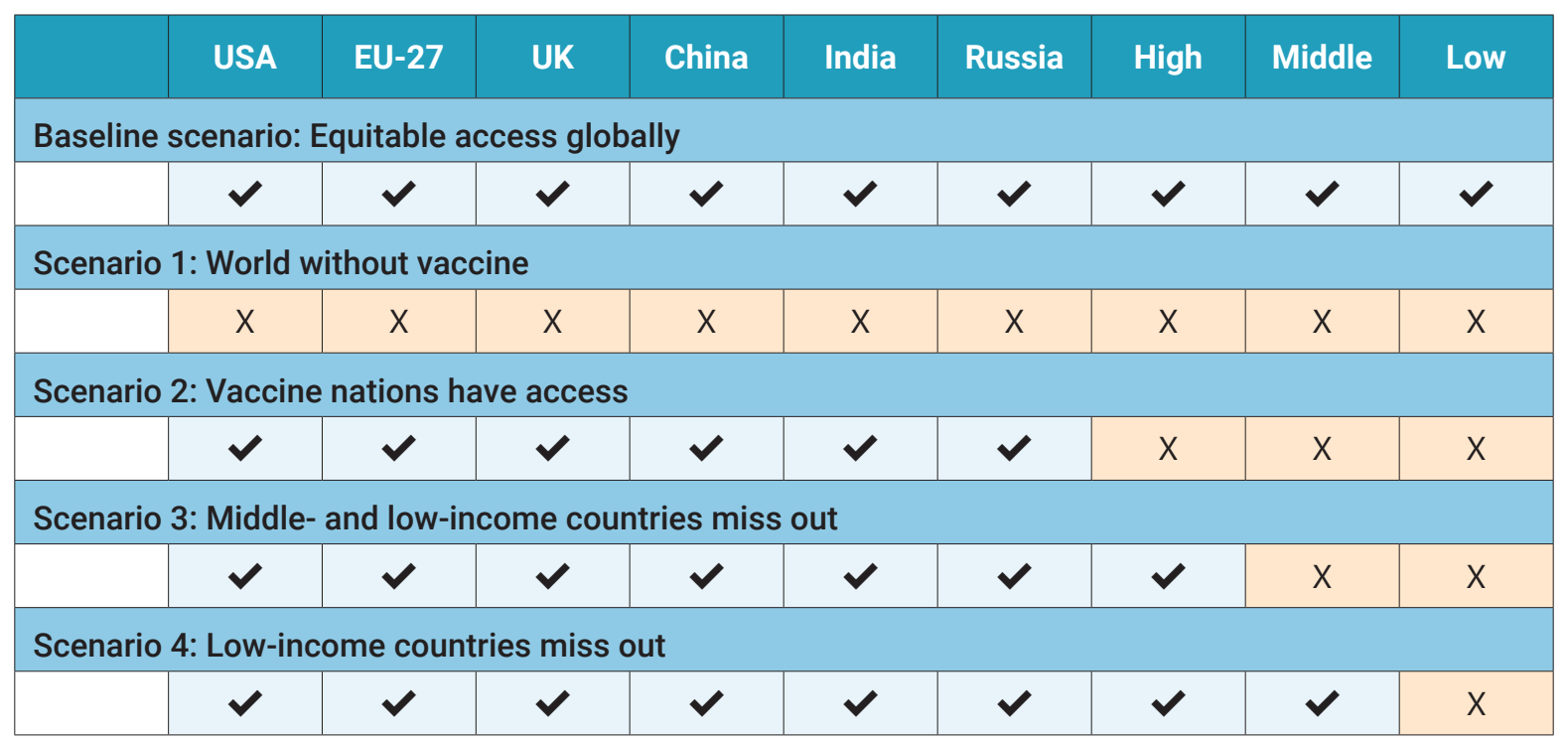

The baseline scenario represents a situation where all countries have access to a vaccine, and they manage to immunise sufficiently their populations against the virus. Physical distancing rules and regulations are eased, allowing economic activity in the five contact-intensive sectors to gradually resume to levels experienced before the pandemic.

In scenario 1, no country or region in the world has access to a vaccine and the full economic implications of the sub-optimal functioning of the contact-intensive sectors described above apply. This reflects the economic situation in a post-lockdown and pre-vaccine situation where tight physical distancing rules and regulations continue to stay in place in order to reduce the spread of the virus.

In scenario 2 it is assumed that the USA, the EU-27, the UK, China, India and Russia simultaneously have access to a vaccine and can sufficiently inoculate their populations. These countries or regions have been selected as they are currently most often mentioned as potential candidates for having early access to a vaccine. Scenario 3 assumes that all other high-income countries have simultaneous access to a vaccine and can sufficiently inoculate their populations against the virus. Scenario 4 further assumes that in addition all middle-income countries have access to a vaccine but not the low-income or poorest countries.

The outcomes of scenarios 2, 3 and 4 highlight to what extent countries are affected by a reduction in foreign demand since other countries have not yet brought under control the COVID19 pandemic domestically. That is, it is assumed that domestic demand in the contact-intensive sectors will improve to pre-pandemic levels, but the share of internationally traded services, either 
as intermediate or final services, will still be negatively affected as under scenario 1. In other words, sectors such as tourism, travel and transportation will largely continue to be negatively affected.

\subsection{The economic effects of inequitable access to COVID-19 vaccines on economic output}

For each of the four scenarios, Tables 3.5 and 3.6 report the changes in real annual GDP in per cent and in absolute values (US \$bn) compared to a (hypothetical) baseline scenario where every country can sufficiently inoculate its population against the virus. ${ }^{10}$ For each scenario the changes in GDP are presented for the base case value parameter assumptions $(M)$, in addition to the lower $(L)$ and higher $(H)$ value assumptions based on the sensitivity analysis.

Our findings suggest that, even in the absence of large-scale containment and closure measures, reduced economic activity in five contact-intensive sectors could reduce global GDP annually by about 3.7 per cent compared to a baseline scenario in which there is equitable access to COVID19 vaccines and where the global population is sufficiently inoculated.

Table 3.5. Per cent change in real annual GDP relative to baseline - scenarios 1 to 4

\begin{tabular}{|c|c|c|c|c|c|c|c|c|c|c|c|}
\hline \multicolumn{2}{|l|}{ Scenario } & World & USA & EU-27 & UK & China & India & Russia & High & Middle & Low \\
\hline \multirow{3}{*}{ Scenario 1} & M & -3.7 & -2.2 & -5.6 & -4.3 & -2.6 & -3.2 & -2.4 & -4.0 & -3.9 & -4.1 \\
\hline & $L$ & -1.5 & -0.9 & -2.3 & -1.7 & -1.0 & -1.3 & -1.0 & -1.6 & -1.6 & -1.7 \\
\hline & $H$ & -7.2 & -4.6 & -10.7 & -8.3 & -5.4 & -6.2 & -4.7 & -7.8 & -7.4 & -7.9 \\
\hline \multirow{3}{*}{ Scenario 2} & M & -1.3 & -0.6 & -1.8 & -1.2 & -0.8 & -0.9 & -0.8 & -1.8 & -1.7 & -1.7 \\
\hline & $L$ & -0.5 & -0.2 & -0.7 & -0.5 & -0.3 & -0.4 & -0.3 & -0.7 & -0.7 & -0.6 \\
\hline & $H$ & -2.6 & -1.2 & -3.4 & -2.3 & -1.6 & -1.8 & -1.6 & -3.8 & -3.5 & -3.4 \\
\hline \multirow{3}{*}{ Scenario 3} & M & -0.3 & -0.1 & -0.4 & -0.3 & -0.2 & -0.2 & -0.2 & -0.3 & -0.8 & -0.7 \\
\hline & $L$ & -0.1 & -0.1 & -0.2 & -0.1 & -0.1 & -0.1 & -0.1 & -0.1 & -0.3 & -0.2 \\
\hline & $H$ & -0.6 & -0.3 & -0.8 & -0.6 & -0.4 & -0.5 & -0.4 & -0.6 & -1.7 & -1.8 \\
\hline \multirow{3}{*}{ Scenario 4} & M & -0.2 & -0.1 & -0.2 & -0.2 & -0.1 & -0.1 & -0.1 & -0.2 & -0.2 & -0.6 \\
\hline & $L$ & -0.1 & 0.0 & -0.1 & -0.1 & 0.0 & -0.1 & 0.0 & -0.1 & -0.1 & -0.2 \\
\hline & $H$ & -0.3 & -0.1 & -0.4 & -0.3 & -0.2 & -0.2 & -0.2 & -0.3 & -0.3 & -1.5 \\
\hline
\end{tabular}

Note: entries report per cent change in real annual GDP relative to the baseline scenario where all countries have full access to a COVID-19 vaccine and can inoculate sufficiently their population. ' $M$ ', 'L', and 'H' represent the estimated changes in GDP based on the base case, lower and higher value parameter assumptions for the change in sectorial activity and corresponding elasticities (see Appendix A for more detail). point in time but always compares the economic output measured in GDP between the baseline scenario and scenarios 1 to 4 and the difference in either per cent or absolute values of GDP can be misunderstood. For instance, if in a scenario for a country shows a reduction of 5 per cent of GDP compared to baseline, then this means that in that given year, GDP is 5 per cent lower than it would otherwise have been (e.g. in the absence of inequitable global access to vaccines). However, if that country is growing year-on-year by 2 per cent at baseline, then the change in GDP between two given years is not 5 per cent but minus three per cent compared to the previous year. 
As reported in Table 3.6, this corresponds to about $\$ 3,339 \mathrm{bn}$ per year and represents the value in GDP the world loses annually until a safe and effective vaccine has been developed, distributed and sufficiently applied across the globe. ${ }^{11}$ This is much smaller than the predicted economic cost of COVID-19 in other studies. McKibbin \& Fernando (2020), for example, estimate the total loss in world GDP to be up to $\$ 14.7$ trillion in 2020 , or about 10.5 per cent. Our estimate is lower because it only takes into account the potential economic loss associated with five contactintensive sectors running at COVID-induced lower levels of economic activity, aiming to represent an economy that is out of the most stringent quarantine and lockdown measures but is still restricted by (mandatory and voluntary) physical distancing rules and regulations. Our estimates are aligned in magnitude to a study that focused only on the economic impact of COVID-19 on the tourism sector, which estimated the economic cost of COVID-19 impact on tourism to be between $\$ 1.2$ trillion $^{12}$ to $\$ 3.3$ trillion $^{13}$ per year (UNCTAD 2020).

Table 3.6. Change in real annual GDP in \$bn relative to baseline - scenarios 1 to 4

\begin{tabular}{|c|c|c|c|c|c|c|c|c|c|c|c|}
\hline \multicolumn{2}{|l|}{ Scenario } & World & USA & EU-27 & UK & China & India & Russia & High & Middle & Low \\
\hline \multirow{3}{*}{ Scenario 1} & $M$ & $-3,449$ & -480 & -983 & -145 & -356 & -88 & -52 & -997 & -147 & -200 \\
\hline & $L$ & $-1,389$ & -183 & -405 & -59 & -139 & -36 & -21 & -404 & -60 & -82 \\
\hline & $H$ & $-6,783$ & -987 & $-1,885$ & -282 & -742 & -172 & -101 & $-1,943$ & -283 & -387 \\
\hline \multirow{3}{*}{ Scenario 2} & $M$ & $-1,232$ & -127 & -311 & -41 & -110 & -26 & -18 & -453 & -65 & -82 \\
\hline & $L$ & -492 & -53 & -129 & -17 & -45 & -11 & -7 & -173 & -25 & -32 \\
\hline & $H$ & $-2,460$ & -246 & -596 & -78 & -213 & -51 & -34 & -942 & -132 & -168 \\
\hline \multirow{3}{*}{ Scenario 3} & $M$ & -292 & -30 & -76 & -10 & -27 & -7 & -5 & -73 & -30 & -35 \\
\hline & $L$ & -115 & -12 & -31 & -4 & -11 & -3 & -2 & -30 & -11 & -11 \\
\hline & $H$ & -594 & -59 & -749 & -19 & -52 & -13 & -9 & -142 & -66 & -86 \\
\hline \multirow{3}{*}{ Scenario 4} & M & -153 & -16 & -40 & -5 & -14 & -3 & -2 & -39 & -6 & -28 \\
\hline & $L$ & -60 & -6 & -17 & -2 & -6 & -1 & -1 & -16 & -2 & -8 \\
\hline & $H$ & -374 & -30 & -78 & -10 & -27 & -7 & -4 & -74 & -17 & -72 \\
\hline
\end{tabular}

Note: entries report changes in real annual GDP (US \$bn, 2019 values) relative to the baseline scenario where all countries have full access to a COVID-19 vaccine and can sufficiently inoculate their population. ' $M$ ', 'L', and 'H' represent the estimated changes in GDP based on the base case, lower and higher value parameter assumptions for the change in sectorial activity and corresponding elasticities (see Appendix A for more detail).

Across the countries or regions included in the analysis the estimated GDP loss varies. For the US we estimate a 2.2 per cent relative loss in annual GDP, corresponding to about $\$ 480 \mathrm{bn}$. For the made. Note that the estimated values in the model analysis are normalised to a year. Assuming linearity, one could break the estimated cost down to a monthly basis by dividing the annual figure by 12 , which is the equivalent of about $\$ 278 b n$ a month. Sensitivity analysis suggests that the estimate varies between \$116bn to \$565bn a month. 
EU-27 we estimate a loss of about 5.6 per cent, corresponding to about $\$ 983 \mathrm{bn}$. The estimated GDP loss for the UK is about 4.3 per cent corresponding to an annual loss of about $\$ 145 \mathrm{bn}$. The estimated loss for the EU-27 and the UK is higher than for the US, which could be explained by the higher relative importance of the tourism sector for many EU-27 countries (Thiessen 2020), ${ }^{14}$ or the relative importance of services (domestic and international trade) to the overall UK economy (Austin 2020).

Furthermore, under scenario 1, the estimated GDP losses for China are 2.6 per cent; for India, 3.2 per cent, and for Russia 2.4 per cent. For the remaining regions, the estimated GDP loss for other high-income countries is 4 per cent annually, for the middle-income countries 3.9 per cent and for the low-income countries 4.1 per cent.

In scenario 2, it is estimated that if the countries that are currently actively developing a vaccine (e.g. USA, EU-27, UK, China, India and Russia) are successful in this endeavour and can inoculate a sufficiently large share of their population, the estimated loss for the world economy in GDP terms would reduce to about 1.3 per cent, corresponding to about $\$ 1,232 \mathrm{bn}$ per year. ${ }^{15}$ Compared to scenario 1, this represents an improvement of 2.4 percentage points or about $\$ 2,217 \mathrm{bn}$ in GDP terms on average per year. However, even though some of the largest economies in the world are assumed to have access to vaccines, we still observe a GDP loss for all countries or regions, compared to the baseline scenario where everyone has access. For instance, the US is still estimated to lose about 0.6 per cent of its GDP annually, compared to the baseline scenario where all countries have access to a vaccine. The EU-27 still loses about 1.8 per cent; the UK about 1.2 per cent; China about 0.8 per cent; India about 0.9 per cent; and Russia about 0.8 per cent. Those regions assumed not to have access to vaccines, at least initially, such as other high-income countries, middle-income countries or low-income countries, also gain compared to scenario 1, due to increased foreign demand from those countries having access, but to a relative lesser extent. For instance, the other high-income countries are still estimated to lose about 1.8 per cent; and the middle- and lower-income countries about 1.7 per cent.

If all other high-income countries manage to have access to a vaccine and would be able to immunise their population (scenario 3), the estimated global GDP loss reduces further to 0.3 per cent, or the equivalent of about $\$ 292 \mathrm{bn}$ per year. In other words, the cost to the world economy for middle- and low-income countries not having access to COVID-19 vaccines is approximately \$24bn per month. ${ }^{16}$

Even if just the low-income countries would miss out on access to COVID-19 vaccines initially (scenario 4), our findings suggest that global GDP would still be about 0.2 per cent lower than it could otherwise be, which corresponds to about \$153bn annually. In other words, as long as the lowest income countries would not have access to a vaccine and are able to immunise their populations sufficiently, the cost the global economy in GDP terms are still about \$13bn a month. Broken down by region, the US would still lose about \$16bn a year; the EU-27 about \$40bn; the

14 In the GTAP data, tourism is not a separate sector but most of its activities are divided into the hospitality and recreation service sectors.

15 Or an estimated \$102bn per month.

16 Calculated by dividing \$292bn by 12 and assuming linearity in the value of GDP each month. 
UK about \$5bn; China about \$14 bn; India about \$3bn; Russia about \$2bn; the other high-income countries about \$39bn; middle-income countries about \$6bn; and low-income countries would still lose about \$28bn annually. For each of the combined regions, EU-27, high-, middle-, and lowincome countries, Appendix B provides a separate breakdown by country of the estimated GDP losses by scenario.

\subsection{Implications}

The findings of the economic analysis presented in this chapter suggest that even in a postlockdown and pre-vaccine situation, where most stringent containment and closure policies have been eased, the COVID-19 pandemic will most likely continue to negatively affect particular sectors in the economy, especially contact-intensive sectors such as travel, tourism and transport. We estimate that the annual loss in global GDP associated with COVID-19-related impaired activity in highly contact-intensive services sectors to be about \$3.4 trillion, if COVID-19 vaccines have not been made available to inoculate the world population. Based on sensitivity analysis this estimate varies between $\$ 1.4$ trillion to $\$ 6.8$ trillion. If only a few countries or regions, such as the US, the UK the EU-27, China, India or Russia, have initially access to a vaccine, their economies would indeed improve substantially but their economic recovery would still depend on concurrent recovery in other regions that have not been able to sufficiently immunise their populations against the virus.

We show that even if only the lowest-income countries initially have no access to a COVID-19 vaccine, the global economy would still lose about \$153bn a year, or approximately \$13bn a month. ${ }^{17}$ As outlined in Table 3.6, all high-income countries, as well as countries such as India, China and Russia, would still incur together an estimated GDP loss of about $\$ 119 \mathrm{bn}$ a year, or approximately about $\$ 10 \mathrm{bn}$ a month,,$^{18}$ compared to a scenario where all countries have access to a vaccine and can inoculate their populations sufficiently. Previously, it has been estimated that the cost of procuring and delivering a safe and effective vaccine to the world's poorest countries would be about $\$ 25 \mathrm{bn}$ (Oxfam International 2020). Based on this cost estimate, our findings would suggest that investing in the access to COVID-19 vaccines for the lower income countries represents a potentially sound strategy for wealthier countries, with a benefit-to-cost ratio of between 1.9 and $12.6,{ }^{19}$ or in other words, every $\$ 1$ invested would provide an approximate return of between $\$ 1.9$ and $\$ 12.6$, with a base case value estimate of $\$ 4.8 .{ }^{20}$ Even if the true cost of providing a vaccine and sufficiently immunising the lowest income countries is higher than $\$ 25 \mathrm{bn}$, as long as the cost is lower than between $\$ 49 \mathrm{bn}$ to $\$ 230 \mathrm{bn}$, from an economic perspective this could still be an optimal strategy, making at least one better off without making another one worse off. \$26bn a month.

18 Based on sensitivity analysis the estimate varies between $\$ 49 b n$ to $\$ 230 b n$ a year, or $\$ 4 b n$ to $\$ 19 b n$ a month.

19 This implicitly assumes that vaccinations would have to be applied on a regular basis, akin to a flu vaccine. If life-time immunity could be achieved with a single treatment, the benefit to cost ratio would be larger if the one-off cost is compared against the long-term economic costs avoided through the application of the vaccine. 


\subsection{Limitations}

The application of a CGE modelling framework to assess the economic implications of inequitable access to COVID-19 vaccines across countries presented in this chapter has several strengths, such as the ability to take into account the economic interdependencies between different sectors (e.g. goods and services) domestically but also through international trade. However, there are some limitations to the modelling approach taken.

Firstly, the scenario-based analysis centers on the assumption that if a vaccine is available, countries with access to it would manage to immunise sufficiently their populations. ${ }^{21}$ This is of course a simplifying assumption as it is not certain that all parts of the population would voluntarily choose to be immunised with a potential vaccine if it is available. Furthermore, there is still a great deal of uncertainty around whether the currently developed vaccine candidates will be able to protect most population groups or would be less effective for some (e.g. the elderly). Low vaccination rates would mean that the estimated benefits of access to COVID-19 vaccines ${ }^{22}$ reported in this chapter represent an upper-bound value estimate.

Secondly, the CGE model analysis is not intended to provide an exact forecast of the world economy at a given point in time in the future. The deterministic model does not consider transitory (stochastic) short-term changes to the overall economic growth path. The aim of the applied modelling framework is to examine the effects of relative changes across different modelling parameters representing different scenarios and then to compare how the economy of a country would change relative to the baseline, holding all other factors constant. This is a simplification of how events would affect the economy in reality; however, it allows the analysis of specific factors in isolation (in our analysis the COVID-19-induced lower economic activity in contact-intensive sectors).

Thirdly, the scenario analysis presented in this chapter depends heavily on assumptions and parameter value inputs from sources outside of the model. This is common in the CGE modelling approach (e.g. see Maliszewska et al. 2020), but it has to be highlighted as a limitation. For instance, the underlying values for changes in economic activity in contact-intensive sectors is calibrated on input data from Sweden and then further modified and applied to all countries or regions in the analysis. However, in the absence of more available empirical data it is difficult to assess the full validity of this assumption. To address some of the uncertainties around the parameter assumptions made, we ran sensitivity analysis using conservative baseline value assumptions with corresponding sensitivity ranges which are based on lower and higher value assumptions based on given ranges of existing estimates of some of the key input parameters. In the future it will be possible to amend some assumptions using better empirical evidence that may emerge.

Finally, the underlying economic equations that mimic the economic behavior of different agents such as households, firms or the government are fixed within the model structure. These model 
parameters determine, for instance, the production technology of firms or how individuals' value different types of goods. There are very good reasons to assume that a massive global issue such as the COVID-19 pandemic could represent a tipping point with long-lasting effects on an economy, for instance by changing the economic behavior of households (e.g. changes in consumption patterns and saving rates), or by triggering the development or uptake of new technologies (e.g. more environmentally friendly technologies) or a change in overall government spending patterns (e.g. away from defense to public health spending). However, as it is difficult to assess ex ante whether and how these behavioral changes would evolve, we have kept them fixed in the model. 



\section{Discussion}

The previous two chapters examined some of the negative implications of 'vaccine nationalism' in terms of how it could affect global equitable access to COVID-19 vaccine candidates and analysed some of the economic costs associated with inequitable access across countries. In what follows we summarise the key insights from this study and provide recommendations on how to potentially reduce the risks of inequitable access to COVID-19 vaccines.

\subsection{The availability of safe and effective vaccines is critical to mitigating the prolonged economic damage of the COVID-19 crisis}

At present, the world economy is likely undergoing a larger economic contraction than seen during the 2008/2009 recession. A large part of the economic damage has been caused by widespread containment and closure measures which have seen many economic sectors having to curtail or cease operations, causing an unprecedented economic downturn. Without vaccines against COVID-19, physical distancing measures and regulations will most likely continue to cause economic sectors that rely on close physical interaction to perform sub-optimally. We find that, depending on the assumptions made about the impact of COVID-19 on contact-intensive service sectors, between $\$ 1.4$ trillion and $\$ 6.8$ trillion globally in GDP terms could be lost annually, even in the absence of large-scale containment and closure measures as experienced during the first months of the pandemic in many countries. This is because contact-intensive service sectors have been significantly disrupted by the new requirements set by national governments and regulators that aim to mitigate the spread of the virus. Transportation, for example, is a very important service sector that acts as an intermediate input in many other sectors, domestically and abroad through international trade. Other sectors such as hospitality and recreation are key for global tourism demand, while tourism itself represents an important pillar of economic output in many countries around the world (UNCTAD 2020).

\subsection{The development and distribution of vaccines could be seen as global public goods}

Given the potential positive health and economic externalities, developing COVID-19 vaccines and ensuring equitable access across the world could be seen as public goods. Therefore, the aim of vaccine development and distribution in the current pandemic would be to accelerate the development of vaccines, distribute promising vaccines globally as soon as possible, and 
support a programme of inoculation over time. This requires an international effort to cooperate supported by the leading global economies. At present, these efforts have not necessarily been driven by those leading economies.

Non-governmental and non-profit organisations have taken two main steps to reduce the risk of 'vaccine nationalism' or global competition in the case of COVID-19. Firstly, CEPI (the Coalition for Epidemic Preparedness Innovations; CEPI 2020), the Bill \& Melinda Gates Foundation, the non-governmental vaccine partnership known as GAVI (2020) and other donors have developed plans to invest early in the production and distribution of promising vaccine candidates. Indeed, they have done so even before the safety and efficacy of these possible vaccines have been established (Dunn 2020). The hope is that this early investment will reduce delays in the production of vaccines and their distribution in poorer countries. However, shortening delays in this manner does not address the production and distribution capacity, especially in some middleincome countries such South Africa, and many Latin American countries. They do not meet the criteria for receiving donor assistance. The approach also competes with better-resourced national initiatives and as such it does not necessarily offset the competitive advantage that national approaches have. For instance, the initiative would not redress the problem that governments in countries that develop and manufacture the vaccines might hoard vaccine above their populations' need, regardless of the negative consequences thereof elsewhere.

A second approach is to try to eliminate the delay in distribution altogether. More than a dozen countries and philanthropies made initial pledges of $\$ 8 \mathrm{bn}$ to the Access to COVID-19 Tools (ACT) Accelerator managed by the World Health Organization (WHO 2020a). This initiative is dedicated to the rapid development and equitable deployment of vaccines, therapeutics and diagnostics for COVID-19. The aim is to make knowledge freely available to all countries and ensure adequate production capacity. Critical factors here are whether countries and large non-profits will pledge adequate resources and whether enough productive capacity can be developed to enable largescale production of vaccines and subsequent equitable distribution.

\subsection{At present it is feared that global competition around vaccine allocation will dominate in the short run}

Currently, vaccine allocation resembles the classic game theory problem known as 'the prisoner's dilemma': all countries cooperating and working together would represent the better outcome but due to a lack of incentives and most likely information asymmetries most countries do not cooperate. This leads to 'vaccine nationalism'. A recent paper by Bollyky \& Bown (2020) explains the issues associated with it from a game theory perspective.

The ACT promoted by the WHO struggled to attract some of the major vaccine-manufacturing states, including the US (Nebehay 2020). In the US, the Trump administration has instead devoted nearly $\$ 10 \mathrm{bn}$ to Operation Warp Speed. This operation aims to deliver hundreds of millions of COVID-19 vaccines by January 2021. However, the focus is very much to inoculate Americans first. India's government and the Serum Institute has considered a similar approach, with an undertaking that any vaccine produced domestically will likely first go to India's 1.3 billion people. Other vaccine developers have made similar statements, pledging that host governments or advanced purchasers will get the early doses if supplies are limited initially. The main aim for 
some countries is to deliver vaccines for their own citizens first before helping others globally. These efforts focus not only on domestic development of vaccines but also on procuring vaccines being developed globally in order to have first access to them as they are produced.

Given the lack of confidence that any cooperative effort would be able to overcome such national efforts, more and more countries have tried to secure their own supplies. France, Germany, Italy and the Netherlands formed the Inclusive Vaccine Alliance to jointly negotiate with vaccine developers and producers. That alliance is now part of a larger European Commission effort to negotiate with manufacturers on behalf of EU member states to arrange for advance contracts and to reserve doses of promising candidates. Evidence from previous virus outbreaks suggests that a 'my nation first' approach is likely. During the swine flu outbreak in 2009, Australia limited the export of vaccines to the US until it had immunised its own population. The Obama administration went back on a pledge to donate vaccines to poor countries and decided to focus on domestic distribution (Milne \& Crow 2020). In the case of COVID-19, initial experiences in the current crisis point to nationalist approaches potentially dominating. In the summer of 2020 , the US bought up the entire global supply of Remdesivir, one of the first drugs proven to work against COVID-19. It seems that most wealthy countries are engaging in similar national efforts to secure supplies of drugs and vaccines, undermining the global cooperative efforts to develop and distribute vaccines that they are nominally supporting but perhaps not providing with enough resources.

\subsection{The cost of vaccine development and distribution is modest compared to the likely prolonged economic costs associated with COVID-19}

The Economist reported recently on the relatively small sums that leading economies were spending on vaccine development and distribution (Economist 2020b). It puts the total figure at close to $\$ 10 \mathrm{bn}$. This pales in comparison with the $\$ 7$ trillion that it claims national governments have announced in support measures to safeguard jobs and incomes or the close to 8 per cent in global GDP reduction during the first stage of the pandemic in the first half of 2020. It seems to make sense to provide wider resources to vaccine development and distribution globally given the significant economic benefits associated with reducing the economic damage caused by COVID-19. Time is an important factor as well. Economic damage accumulates over weeks and months. So, having a viable vaccine available even a week earlier may reduce the economic costs associated with COVID-19 substantially. Our analysis points to a cost of between $\$ 116 \mathrm{bn}$ and \$565bn a month in lost GDP to the world economy from not having access to a vaccine. Taking the numbers reported in the Economist and comparing them to what we observe in the findings of this report, the current resources expended on vaccine development and allocation are relatively small compared to the economic loss associated with COVID-19. As such, only a small fraction of the potential economic benefits of having an effective vaccine and distributing it sufficiently is currently expended on vaccine development. A logical conclusion is that there is a strong business case for leading economies to invest substantially more in vaccine development and distribution. This could form the basis for boosting the global cooperative effort. 
In order to expand investments and ensure a sufficient supply of a potential COVID-19 vaccine, some argue for the establishment of advanced market commitments (AMCs), which have shown potential to accelerate access to vaccines that would not otherwise be available for many years, especially in the context of developing countries (Kremer et al. 2020; Kremer \& Glennerster 2004). An AMC is a financial commitment from donors to subsidise the future purchase of a vaccine not yet available, if an appropriate vaccine is developed. In other words, an AMC is a funding mechanism to incentivise vaccine makers to produce suitable vaccines needed at a sustainable price and thus to invest in the necessary research and manufacturing capacity. A 'sustainable price' needs to be a price that is both affordable to all countries and provides enough incentive to manufacturers to develop vaccines. An AMC is not a purchase guarantee, as industry will only receive the subsidised price if the product meets targeted standards, if countries demand the product, and if an affordable, long-term price can be negotiated with the individual vaccine manufacturers (i.e. conditional on the price being set close to the firm's marginal cost). If multiple vaccines are developed, the AMC fund will have authority to choose products to purchase based on efficacy, the availability of sufficient vaccine for timely immunisation or suitability for different population groups (Athey et al. 2020).

\subsection{Even if nationalistic behaviour is inevitable, there are economic incentives to provide access to vaccines across the globe as soon as possible}

In the traditional game theory problem, the prisoner's dilemma, the prisoners would benefit from cooperating. Our economic analysis suggests that there are distinct benefits associated with ensuring that countries have equitable access to the vaccines that are being developed.

Our findings suggest that if some countries in the world do not have access to vaccines and cannot inoculate their populations sufficiently, there will be prolonged economic costs associated with COVID-19 for all countries. We find that even if only low-income countries are denied access to vaccines initially, the economies of high-income countries and those of India, China and Russia would still lose annually between $\$ 49 \mathrm{bn}$ and $\$ 230 \mathrm{bn}$ a year. This is a higher figure than the $\$ 25 \mathrm{bn}$ estimated cost of immunising the populations of low-income countries. Even though $\$ 49 b n-\$ 230 b n$ is a relatively small amount at face value, compared to what many countries currently are spending on government programmes to safeguard their economies during the pandemic, it also means that wealthier countries could channel significant funds into facilities that try to pool resources for an equitable global access to vaccines, such as COVAX, without being economically worse off. For instance, based on existing cost estimates, we show that for high-income countries, every $\$ 1$ invested would provide an approximate return of between $\$ 1.9$ and \$12.6. 


\subsection{There may also be unintended consequences associated with global competition or vaccine nationalism}

It is hard to know in advance how effective a single vaccine will be and for which population groups. It could be that vaccine $\mathrm{A}$ is more effective for older people and vaccine B more practical for younger people. Several vaccines could prove to be ineffective. Vaccine $\mathrm{C}$ may be less effective but easier to administer. There may be trade-offs and relative benefits associated with different vaccines. This would mean that it would be unwise to bet on one vaccine. It would be a better strategy to share vaccines as they come to the market.

Allocating COVID-19 vaccines will not be a one-off experience: multiple safe and effective vaccines may eventually emerge, each with different strengths and benefits. If one country were to deny others access to an early vaccine, those other countries could be expected to reciprocate by withholding potentially more effective vaccines they might develop later. And game theory makes clear that, even for the most selfish players, incentives for cooperation improve when the game is repeated, and players can credibly threaten quick and effective 'punishment' for not upholding to previous commitments.

Global competition may also prevent the vaccine reaching those most in need. Though much remains unknown about why certain people are more affected by COVID-19 than others, there are people in certain risk groups that are more likely to develop severe and lasting symptoms because of the virus. Our knowledge of these risk factors is improving (Economist 2020c). In terms of vaccine distribution, we may wish to prioritise vulnerable people in order to avoid the most severe cases. Similarly, we may wish to inoculate key workers first to ensure that they can continue to provide the highest levels of care and support. Both actions could have significant societal benefits and enable global health services to cope. Global competition may mean that vulnerable people in certain countries receive the vaccine after those at low risk in other countries. In short, ineffective allocation of any vaccine would likely over-allocate a vaccine to those in relatively low risk groups, leading to preventable deaths and morbidity. Of course, ineffective allocation can occur within countries as well. For instance, in the early stages of the pandemic when testing capacity was limited there were some reports in the US that the rich found it easier to access tests. The same could occur when a vaccine is available (Twohey et al. 2020). There is a wider discussion needed in many societies around equitable access and how to prioritise vaccine distribution.

It could also be that vaccines need to be administered repeatedly over time to strengthen the immune response to COVID-19. Inoculating a large part of the global population is a massive undertaking and speaks to the development of very significant vaccination programmes. However, the world has a strong history of undertaking such programmes, and the global effort to eradicate polio is a good example that shows the importance of administrative capacity to run a programme but also trust. If the population does not trust the vaccine or programme, then vaccination rates are much lower. If global competition means that in a rush to bring vaccines to the market adequate testing of these vaccines is not undertaken, any side effects may undermine public trust. This may already be happening in the case of Russian vaccine development, where the vaccine may be made available without any efficacy trials (Spinney 2020). Established 'antivax' movements coupled to conspiracy theories on social media could be powerful voices against vaccines, and low vaccination rates will make any programme less effective. 


\subsection{To foster international sharing of vaccines, there is a need for enforceable frameworks in vaccine development and distribution, managed by established international fora}

We see four elements that are important in how global cooperation can be supported: international fora; frameworks; enforceability; and time. Some of these are also discussed in Bollyky \& Bown (2020).

The first element relates to finding an adequate international forum that is credible in terms of building global cooperation. The World Health Organization already provides a forum for such cooperation but its activities have become quite politicised recently. Instead, a forum where world leaders meet with subcommittees may be more appropriate. Bollyky \& Bown (2020) point out that some steps have already been taken in the G-20.

The basic principles of how vaccines should be procured and allocated should be established in a framework. Clearly, any restrictions on supplying other countries, such as export bans and seizures of supplies, can be problematic. We do not here set out in detail what this framework should look like but make the point that a framework should be developed. It would limit trade restrictions and set out the basic principles and contributions that would enable not only the global sharing of knowledge but also more importantly the procurement and allocation of promising vaccines. These activities should be underpinned by the best scientific knowledge.

Enforceability will be key and as such the framework should stipulate how the joint understanding can be enforced. This is important given the trends towards vaccine nationalism. Countries need to be bound to an agreement and not feel that they can limit supplies again when it suits them. Agreements could also build international standards on vaccine development and try to limit the liability of vaccine developers globally. This would provide more clarity for the vaccine developers and also mitigate their risk.

Finally, time is important. Vaccine distribution and development may be a longer-term exercise. We are not sure which vaccines will be effective for which groups, we are not sure whether vaccine doses need to be repeated and we are not sure how long immunity may last. Some populations will be hard to reach and anti-vax campaigners may limit the rates of uptake. The international effort to support vaccination needs to be sustained over time. This also means that the issue of effective vaccination against COVID-19 will probably extend beyond most political cycles. As such, global cooperation could also help to take the short-termism out of decision making and encourage a focus on aspirations for the long-term health of the global population and indeed economic development. 


\section{References}

Abboud, Leila. 2020. 'UK strikes deal for 60m Covid-19 vaccine doses with Sanofi and GSK.' Financial Times, 29 July. As of 23 September 2020: https://www.ft.com/content/4fd94286-66d8-4c6b-b589-da87a92c3715

Alfaro, Tiago Ramos. 2020. 'Transport for London to Place a Quarter of its Staff on Furlough.' Bloomberg, 24 April. As of 23 September 2020: https://www.bloomberg.com/news/articles/2020-04-24/ transport-for-london-to-place-a-quarter-of-its-staff-on-furlough

Andersen, Asger Lau, Emil Toft Hansen, Niels Johannesen \& Adam Sheridan. 2020. 'Pandemic, Shutdown and Consumer Spending: Lessons from Scandinavian Policy Responses to COVID-19.' ArXiv:2005.04630, 10 May. As of 23 September 2020: http://arxiv.org/abs/2005.04630

Apple. 2020. 'Mobility Trends Reports.' As of 23 September 2020:

https://covid19.apple.com/mobility

Athey Susan, Michael Kremer, Christopher Snyder \& Alex Tabarrok. 2020. 'In the Race for a Coronavirus Vaccine, We Must Go Big. Really, Really Big.' New York Times, 4 May. As of 23 September 2020: https://www.nytimes.com/2020/05/04/opinion/coronavirus-vaccine.html

Austin, Amy. 2020. 'UK in Deep Recession as GDP Falls 20.4\%.' FT Adviser, 12 August. As of 23 September 2020:

https://www.ftadviser.com/your-industry/2020/08/12/uk-in-deep-recession-as-gdp-falls-20-4/

Badur, Selim, Martin Ota, Serdar Öztürk, Richard Adegbol \& Anil Dutta. 2020. "Vaccine confidence: the keys to restoring trust." Human vaccines \& immunotherapeutics, 16(5), 1007-1017.

https://doi.org/10.1080/21645515.2020.1740559

Balfour Hannah. 2020. "Who will receive COVID-19 vaccines first?" European Pharmaceutical Review, 12 October. As of 14 October 2020:

https://www.europeanpharmaceuticalreview.com/article/130022/ who-will-receive-covid-19-vaccines-first/

Bernstein, Lenny, \& Frances Stead Sellers. 2020. 'Patients with Heart Attacks, Strokes and Even Appendicitis Vanish from Hospitals.' Washington Post, 19 April. As of 23 September 2020: https://www.washingtonpost.com/health/patients-with-heart-attacks-strokes-and-even-appendicitisvanish-from-hospitals/2020/04/19/9ca3ef24-7eb4-11ea-9040-68981f488eed_story.html 
Bloom, Nicholas, James Liang, John Roberts \& Zhichun Jenny Ying. 2015. 'Does Working from Home Work? Evidence from a Chinese Experiment.' Quarterly Journal of Economics 130(1): 165218. As of 23 September 2020: https://doi.org/10.1093/qje/qju032

Bollyky, Thomas J., \& Chad P. Bown. 2020. 'The Tragedy of Vaccine Nationalism.' Foreign Affairs, 13 August. As of 23 September 2020:

https://www.foreignaffairs.com/articles/united-states/2020-07-27/vaccine-nationalism-pandemic

Bremmer, Ian. 2020. 'What Vaccine Nationalism Means for the Coronavirus Pandemic.' Time Magazine, 27 July. As of 23 September 2020:

https://time.com/5871532/vaccine-nationalism-coronavirus-pandemic/

Brons, Martijn, Eric Pels, Peter Nijkamp \& Piet Rietveld. 2002. 'Price Elasticities of Demand for Passenger Air Travel: A Meta-Analysis.' Journal of Air Transport Management 8(3): 165-75. As of 23 September 2020: https://doi.org/10.1016/S0969-6997(01)00050-3

Cheng, Maria \& Lori Hinnant. 2020. "Push to bring coronavirus vaccines to the poor faces trouble", Associated Press News, 1 October. As of 19 October 2020:

https://apnews.com/article/virus-outbreak-public-health-archive-united-nations-6656cba6143eb0 97da3dc7c8b360bfa4

CEPI. 2020. 'CEPI to fund three programmes to develop vaccines against the novel coronavirus, nCoV-2019.' As of 23 September 2020:

https://cepi.net/news_cepi/cepi-to-fund-three-programmes-to-develop-vaccines-against-thenovel-coronavirus-ncov-2019/

Cookson, Clive. 2020. 'WHO Labels Coronavirus a Pandemic.' Financial Times, 11 March. As of 23 September 2020: https://www.ft.com/content/5946a17c-63bb-11ea-a6cd-df28cc3c6a68

Cookson, Clive, \& Anna Gross. 2020. 'Oxford Coronavirus Vaccine Shows Promise in Early Trial.' Financial Times, 20 July. As of 23 September 2020:

https://www.ft.com/content/10c7306d-dbfa-4a5f-abe5-5748b4083d94

Cookson, Clive, Aime Williams \& James Politi. 2020. 'US Official Hits out at Hoarding of Coronavirus Medical Supplies.' Financial Times, 5 March. As of 23 September 2020:

https://www.ft.com/content/f6bc4950-5efe-11ea-b0ab-339c2307bcd4

Corum, Jonathan, Sui-Lee Wee \& Carl Zimmer. 2020. 'Coronavirus Vaccine Tracker.' New York Times. As of 23 September 2020:

https://www.nytimes.com/interactive/2020/science/coronavirus-vaccine-tracker.html

Crow, David. 2020. 'Merck Chief Casts Doubt on Coronavirus Vaccine Timeframe.' Financial Times, 26 May. As of 23 September 2020:

https://www.ft.com/content/7b72a568-9eed-460f-b100-7bf74e3f4cbf

Davies, Alex. 2020. 'Airlines Use Empty Passenger Jets to Ease the Cargo Crunch.' WIRED, 17

March. As of 23 September 2020:

https://www.wired.com/story/airlines-use-empty-passenger-jets-ease-cargo-crunch/ 
DfID. 2018. 'Statistics on International Development: Final UK Aid Spend 2017.' As of 23

September 2020:

https://www.gov.uk/government/publications/statistics-on-international-development-final-ukaid-spend-2017/statistics-on-international-development-final-uk-aid-spend-2017

Dunkerley, Fay, Charlene Rohr \& Andrew Daly. 2014. 'Road Traffic Demand Elasticities: A Rapid Evidence Assessment.' Santa Monica, Calif.: RAND Corporation. RR-888-DFT. As of 23 September 2020: https://www.rand.org/pubs/research_reports/RR888.html

Dunn, Andrew. 2020. 'A coalition backed by Bill Gates is funding biotechs that are scrambling to develop vaccines for the deadly Wuhan coronavirus.' Business Insider, 23 January. As of 23 September 2020:

https://www.businessinsider.com/vaccines-for-wuhan-china-cornonavirus-moderna-inoviocepi-2020-1

Economist. 2020a. 'The 90\& economy that lockdowns will leave behind.' As of 23 September 2020: https://www.economist.com/briefing/2020/04/30/ the-90-economy-that-lockdowns-will-leave-behind

Economist. 2020b. 'The world is spending nowhere near enough on a coronavirus vaccine.' As of 23 September 2020:

https://www.economist.com/leaders/2020/08/06/

the-world-is-spending-nowhere-near-enough-on-a-coronavirus-vaccine

Economist. 2020c. 'When covid-19 becomes a chronic illness.' As of 23 September 2020:

https://www.economist.com/science-and-technology/2020/08/22/

when-covid-19-becomes-a-chronic-illness

Ellyatt, Holly. 2020. "'Vast” Gap in Funding Needed to Fight the Coronavirus, WHO Warns.' CNBC, 10 August. As of 23 September 2020:

https://www.cnbc.com/2020/08/10/vast-gap-in-funding-needed-to-fight-the-coronavirus-whowarns.html

Evenett, Simon. 2020. " Sickening thy neighbour: Export restraints on medical supplies during a pandemic", Vox EU, 19 March. As of 23 September 2020:

https://voxeu.org/article/export-restraints-medical-supplies-during-pandemic

Famiglietti, Matthew, Fernando Leibovici \& Ana Maria Santacreu. 2020. 'How the Impact of Social Distancing Ripples through the Economy.' Fed in Print, 7 April. As of 23 September 2020:

https://fedinprint.org/item/l00001/87754

Farnam Street. n.d. 'Prisoner's Dilemma: What Game Are You Playing?' As of 23 September 2020: https://fs.blog/2020/02/prisoners-dilemma/

Financial Times. 2020. 'Pandemic Crisis: Global Economic Recovery Tracker.' As of 23 September 2020: https://www.ft.com/content/272354f2-f970-4ae4-a8ae-848c4baf8f4a

Folkhälsomyndigheten (Public Health Agency of Sweden). 2020a. 'Nytt bekräftat fall av covid-19.' As of 23 September 2020:

https://www.folkhalsomyndigheten.se/nyheter-och-press/nyhetsarkiv/2020/februari/

nytt-bekraftat-fall-av-covid-19/ 
Folkhälsomyndigheten (Public Health Agency of Sweden). 2020b. 'Flera tecken på samhällsspridning av covid-19 i Sverige.' As of 23 September 2020:

https://www.folkhalsomyndigheten.se/nyheter-och-press/nyhetsarkiv/2020/mars/

flera-tecken-pa-samhallsspridning-av-covid-19-i-sverige/

Fouquet, Roger. 2012. 'Trends in Income and Price Elasticities of Transport Demand (18502010).' Energy Policy 50: 62-71. As of 23 September 2020:

https://doi.org/10.1016/j.enpol.2012.03.001

GAMS (homepage). 2020. As of 23 September 2020: www.gams.com

GAVI. 2020. 'COVID-19.' As of 23 September 2020: https://www.gavi.org/vaccineswork/covid19

Gertz, Geoffrey. 2020. 'Reopening the World: Coordinating the International Distribution of Medical Goods.' Brookings, 30 June. As of 23 September 2020:

https://www.brookings.edu/blog/up-front/2020/06/30/ reopening-the-world-coordinating-the-international-distribution-of-medical-goods/

Google. 2020. 'COVID-19 Community Mobility Reports.' As of 23 September 2020: https://www.google.com/covid19/mobility/

Gopinath, Gita. 2020. 'The Great Lockdown: Worst Economic Downturn Since the Great Depression.' International Monetary Fund Blog, 14 April. As of 23 September 2020:

https://blogs.imf.org/2020/04/14/the-great-lockdown-worst-economic-downturn-since-the-greatdepression/

Gorlick, Adam. 2020. 'The productivity pitfalls of working from home in the age of COVID-19.' University of Stanford News, 30 March. As of 23 September 2020:

https://news.stanford.edu/2020/03/30/productivity-pitfalls-working-home-age-covid-19/

Gross, Anna. 2020. "'Silver Bullet" to Beat Covid-19 Unlikely, Warns UK Vaccine Chief.' Financial

Times, 29 July. As of 23 September 2020:

https://www.ft.com/content/f63f9e25-a291-4871-9d4b-2fcf93c4969e

Grossman, Shelby. 2019. 'Russia Wants More Influence in Africa. It's Using Disinformation to Get There.' Washington Post, 3 December 2019. As of 23 September 2020:

https://www.washingtonpost.com/politics/2019/12/03/

russia-wants-more-influence-africa-its-using-disinformation-get-there/

Hale, Thomas, Noam Angrist, Emily CameronBlake, Laura Hallas, Beatriz Kira, Saptarshi Majumdar, Anna Petherick, Toby Phillips, Helen Tatlow \& Samuel Webster (2020). "Oxford COVID19 Government Response Tracker" Blavatnik School of Government. As of 23 September: www.bsg.ox.ac.uk/covidtracker

Hanney, Stephen, Steven Wooding, Jon Sussex \& Jonathan Grant. 2020. "From COVID-19 research to vaccine application: why might it take 17 months not 17 years and what are the wider lessons?" Health Research Policy and Systems, 18:61.

Johnson, Carolyn Y., \& Eva Dou. 2020. 'The global race for a coronavirus vaccine could lead to this generation's Sputnik moment.' Washington Post. As of 23 September 2020:

https://www.washingtonpost.com/health/2020/06/03/coronavirus-vaccine-global-race/ 
Khamsi, Roxanne. 2020. 'If a Coronavirus Vaccine Arrives, Can the World Make Enough?' Nature 580(7805): 578-80. As of 23 September 2020: https://doi.org/10.1038/d41586-020-01063-8

Kirby, Jen. 2020. 'The Global Risk of Vaccine Nationalism.' VOX, 27 July. As of 23 September 2020: https://www.vox.com/21327487/covid-19-vaccine-coronavirus-trump-us-china-competition

Kramer, Andrew E. 2020. 'Russia Sets Mass Vaccination for October After Shortened Trial.' New York Times, 2 August. As of 23 September 2020:

https://www.nytimes.com/2020/08/02/world/europe/russia-trials-vaccine-October.html

Kremer, Michael, Jonathan Levin, \& Christopher M. Snyder. 2020. "Advance Market Commitments: Insights from Theory and Experience." AEA Papers and Proceedings, 110: 269-73.

Kremer, Michael \& Rachel. 2004. "Strong Medicine: Creating Incentives for Pharmaceutical Research on Neglected Diseases." Princeton; Oxford: Princeton University Press. doi:10.2307/j. ctt1dr365r

Krisinformation. 2020. 'Förbud mot allmänna sammankomster med fler än 50 personer.' As of 23 September 2020:

https://www.krisinformation.se/nyheter/2020/mars/ytterligare-begransning-sammankomster

Kuchler, Hannah. 2020. 'Moderna Agrees Deal with US Government on Scaling up Testing for Vaccine.' Financial Times, 16 April. As of 23 September 2020:

https://www.ft.com/content/26777f7b-ea48-4727-afdc-c9f6adbc5a13

Kuchler, Hannah, Clive Cookson \& Donato Paolo Mancini. 2020. 'Moderna Pitches Virus Vaccine at about \$50-\$60 per Course.' Financial Times, 28 July. As of 23 September 2020:

https://www.ft.com/content/405c0d07-d15a-4f5b-8a77-3c2fbd5d4c1c

Kuchler, Hannah, David Crow, Andrew Edgecliffe-Johnson \& Demetri Sevastopulo. 2020. 'Trump Considers Fast-Tracking UK Covid-19 Vaccine before US Election.' Financial Times, 24 August. As of 23 September 2020: https://www.ft.com/content/b053f55b-2a8b-436c-8154-0e93dcdb3c1a

Lanz Bruno \& Thomas Rutherford. 2016. "GTAP in GAMS: Multiregional and Small Open Economy Models." Journal of Global Economic Analysis, 1(2):1-77.

Lee, Yern Fai, \& Wenyan Yang. 2020. 'Recovering from COVID-19: the importance of investing in global public goods for health.' UN/DESA Policy Brief No 83. As of 23 September 2020: https://www.un.org/development/desa/dspd/wp-content/uploads/sites/22/2020/07/PB_83.pdf

Lofgren, Hans, Rebecca Lee \& Sherman Robinson. 2002. "A Standard Computable General Equilibrium (CGE) Model in GAMS." International Food Policy Research Institute (IFPRI), Microcomputers in Policy Research No. 5. As of 23 September 2020: http://www.ifpri.org/sites/default/files/publications/mc5.pdf

Maliszewska, Maryla, Aaditya Mattoo \& Dominique van der Mensbrugghe. 2020. The Potential Impact of COVID-19 on GDP and Trade: A Preliminary Assessment. Policy Research Working Papers, World Bank Group. As of 23 September 2020: https://doi.org/10.1596/1813-9450-9211

Mancini, Donato Paolo, \& Michael Peel. 2020. "'Vaccine Nationalism” Delays WHO's Struggling Covax Scheme.' Financial Times, 2 September. As of 23 September 2020: https://www.ft.com/content/502df709-25ac-48f6-aee1-aec7ac03c759 
Mancini, Donato Paolo, Hannah Kuchler, Clive Cookson \& Naomi Rovnick. 2020. 'AstraZeneca Books Orders for 400m Doses of Oxford Vaccine.' Financial Times, 21 May. As of 23 September 2020: https://www.ft.com/content/4b216c2e-2558-4308-b9c2-bf805b08e949

McKibbin, Warwick J., \& Roshen Fernando. 2020. 'Global Macroeconomic Scenarios of the COVID-19 Pandemic.' CAMA Working Paper No. 62/2020. As of 23 September 2020: https://papers.ssrn.com/abstract=3635103

McMorrow, Ryan, \& Jonathan Eley. 2020. 'Why Supermarkets Are Struggling to Profit from the Online Grocery Boom.' Financial Times, 23 July. As of 23 September 2020:

https://www.ft.com/content/b985249c-1ca1-41a8-96b5-0adcc889d57d

Miller, Joe, \& Clive Cookson. 2020. 'Britain Signs up for 90m Doses of German and French Vaccines.' Financial Times, 20 July. As of 23 September 2020:

https://www.ft.com/content/8a74a6a8-923b-47ee-9ff3-29b46e0e532b

Milne, Richard. 2020a. 'Architect of Sweden's No-Lockdown Strategy Insists It Will Pay Off.' Financial Times, 8 May. As of 23 September 2020:

https://www.ft.com/content/a2b4c18c-a5e8-4edc-8047-ade4a82a548d

Milne, Richard. 2020b. 'Sweden Unlikely to Feel Economic Benefit of No-Lockdown Approach.' 10 May. As of 23 September 2020:

https://www.ft.com/content/93105160-dcb4-4721-9e58-a7b262cd4b6e

Milne, Richard, \& David Crow. 2020. 'Why Vaccine "Nationalism" Could Slow Coronavirus Fight.' Financial Times, 14 May. As of 23 September 2020:

https://www.ft.com/content/6d542894-6483-446c-87b0-96c65e89bb2c

Nebehay, Stephanie. 2020. 'WHO decries "vast global gap" in funds needed to fight coronavirus.' MSN News. As of 23 September 2020:

https://www.msn.com/en-au/news/world/who-decries-vast-global-gap-in-funds-needed-to-fightcoronavirus/ar-BB17MxGK

Neville, Sarah, Andrew Bounds, Mure Dickie, Federica Cocco \& Bethan Staton. 2020. "Empty noncoronavirus beds raise fears that sickest are avoiding NHS." Financial Times, 10 April. As of 23 September 2020: https://www.ft.com/content/d5ac0a79-6647-4f49-bb64-d1cc66362043

Oxfam International. 2020. 'Vaccinating poorest half of humanity against coronavirus could cost less than four month's big pharma profits.' Press Release, 14 May. As of 23 September 2020: https://www.oxfam.org/en/press-releases/ vaccinating-poorest-half-humanity-against-coronavirus-could-cost-less-four-months

Peng, Bo, Haiyan Song, Geoffrey I. Crouch \& Stephen F. Witt. 2015. 'A Meta-Analysis of International Tourism Demand Elasticities.' Journal of Travel Research 54 (5): 611-33. As of 23 September 2020: https://doi.org/10.1177/0047287514528283

Powley, Tanya, Claire Bushey \& David Keohane. 2020. 'Aviation Industry Prepares for Sweeping Changes in Post-Pandemic Travel.' Financial Times, 25 May. As of 23 September 2020: https://www.ft.com/content/abc6355a-3801-4e32-a992-f55e475d4454 
Reimer, Jeff, \& Thomas Hertel. 2004. 'International Cross Section Estimates of Demand for Use in the GTAP Model.' GTAP Technical Papers 1647, Center for Global Trade Analysis, Purdue University. As of 23 September 2020: https://ideas.repec.org/p/gta/techpp/1647.html

Reuters. 2020. 'AstraZeneca agrees to supply Europe with 400 man doses of COVID-19 vaccine.' Reuters, 13 June. As of 23 September 2020:

https://uk.reuters.com/article/uk-health-coronavirus-vaccines/ astrazeneca-agrees-to-supply-europe-with-400-m|n-doses-of-covid-19-vaccine-idUKKBN23K015

Ringel, Jeanne S., Susan D. Hosek, Ben A. Vollaard \& Sergej Mahnovski. 2002. 'The Elasticity of Demand for Health Care: A Review of the Literature and Its Application to the Military Health System.' Santa Monica, Calif.: RAND Corporation. MR-1355-OSD. As of 23 September 2020: https://www.rand.org/pubs/monograph_reports/MR1355.html

Rosenberger, Randall S., \& Tom D. Stanley. 2010. 'Publication Selection of Recreation Demand Price Elasticity: A Meta-Analysis.' As of 23 September 2020: https://www.hendrix.edu/uploadedFiles/Departments_and_Programs/Business_and_Economics/ AMAES/MAER\%202010\%20AR\%20Rosenberger\%20Stanley\%20090110.pdf

Roser, Max, Hannah Ritchie, Esteban Ortiz-Ospina \& Joe Hasell. 2020. 'Coronavirus Pandemic (COVID-19).' OurWorldInData.org. As of 23 September 2020:

https://ourworldindata.org/coronavirus

Spinney Laura. 2020. 'How the race for a Covid-19 vaccine is getting dirty.' Guardian, 30 August. As of 23 September 2020 :

https://www.theguardian.com/society/2020/aug/30/how-the-race-for-a-covid-19-vaccine-got-dirty

Statistics Sweden. 2020. 'Production Value Index.' As of 23 September 2020:

https://www.scb.se/en/finding-statistics/statistics-by-subject-area/business-activities/

general-statistics/production-value-index/

Steenhuysen, Julie, \& Kate Kelland 2020. 'Vaccine makers face biggest medical manufacturing challenge in history.' Reuters Business News, 25 June. As of 23 September 2020:

https://www.reuters.com/article/us-health-coronavirus-vaccines-manufactu/ vaccine-makers-face-biggest-medical-manufacturing-challenge-in-history-idUSKBN23W1ND

Sung, Jeremy, \& Yannick Monschauer. 2020. 'Changes in transport behaviour during the Covid-19 crisis.' IEA. As of 23 September 2020:

https://www.iea.org/articles/changes-in-transport-behaviour-during-the-covid-19-crisis

Thiessen, Tamara. 2020. 'US Travel Ban: This Is How It's Costing Europe Billions.' Forbes, 4 July. As of 23 September 2020:

https://www.forbes.com/sites/tamarathiessen/2020/07/04/us-travel-ban-costing-europe-billions/

Twohey, Megan, Steve Eder \& Marc Stein. 2020. 'Need a Coronavirus Test? Being Rich and Famous May Help.' New York Times, 18 March. As of 23 September 2020: https://www.nytimes.com/2020/03/18/us/coronavirus-testing-elite.html

UNCTAD. 2020. 'COVID-19 and Tourism.' As of 23 September 2020:

https://unctad.org/en/PublicationsLibrary/ditcinf2020d3_en.pdf 
University of Oxford. 2020. 'Landmark partnership announced for development of COVID-19 vaccine.' As of 23 September 2020:

https://www.ox.ac.uk/news/2020-04-30-landmark-partnership-announced-development-covid-19vaccine

WHO. 2020a. 'The Access to COVID-19 Tools (ACT) Accelerator'. As of 23 September 2020: https://www.who.int/initiatives/act-accelerator

WHO. 2020b. 'The COVAX facility. Global procurement for COVID-19 vaccines.' As of 23 September 2020:

https://www.who.int/publications/m/item/the-covax-facility

Wright, Robert. 2020. 'UK's Light-Touch Quarantine Poses Enforcement Questions.' Financial Times, 17 August. As of 23 September 2020:

https://www.ft.com/content/f96d8a8b-52ea-452b-a578-e9d0363cf16e

WTO. 2020. 'Trade Costs in the Time of Global Pandemic.' As of 23 September 2020:

https://www.wto.org/english/tratop_e/covid19_e/trade_costs_report_e.pdf

Yamey, Gavin, Marco Schäferhoff, Muhammad Pate, Mukesh Chawla, Kent Ranson, Richard Hatchett \& Richard Wilder. 2020. 'Funding the Development and Manufacturing of COVID-19 Vaccines.' Duke Global Working Paper Series No. 20. As of 23 September 2020:

https://doi.org/10.2139/ssrn.3575660

Yaqub, Ohid, Sophie Castle-Clarke, Nick Sevdalis \& Joanna Chataway. 2014. 'Attitudes to Vaccination: A Critical Review.' Social Science \& Medicine 112: 1-11. As of 23 September 2020: https://doi.org/10.1016/j.socscimed.2014.04.018

Yu, Sun, \& Wang Xueqiao. 2020. 'Chinese Businesses Adapt to Post-Lockdown Reality.' Financial Times, 8 June. As of 23 September 2020:

https://www.ft.com/content/6873359d-d3e2-4cb2-9f61-ca8c262ddaf3 


\section{Appendix A: The macroeconomic modelling framework}

\section{A.1. The macroeconomic model}

We used a multi-country, multi-sector computable general equilibrium (CGE) model to quantify the potential global economic situation in a post-lockdown pre-vaccine COVID-19 world and then to assess the economic implications of inequitable access to COVID-19 vaccines between countries or global regions. The model represents the full economy of a given country or region. As discussed by Lofgren et al. (2002), a CGE model is essentially a large numerical macroeconomic model that combines economic theory with real economic data in order to derive the economic impacts of events in an economy. Our core model, numerically simulated with the computer program GAMS (2020), using the MPSGE solver (Rutherford 1999), resembles that of Lanz \& Rutherford (2016).

\section{A.1.1. Model description}

CGE models arrive at their outputs by capturing the behaviour of different economic agents in the economy, including (1) firms; (2) consumers; (3) government; and (4) foreign agents. Firms seek to combine factor inputs such as capital and labour to maximise profits; consumers allocate their disposable income between savings and consumption to maximise their welfare; the government levies and collects taxes, distributes social benefits but also purchases goods; and foreign agents interact with domestic agents through international trade and international factor flows (e.g. migration, foreign direct investment). The behaviour of each of the agents is based on economic theory and specified mathematically as a system of equations that is solved simultaneously to obtain a situation in which all markets are cleared (i.e. supply equals demand), which is called an 'equilibrium'. In addition, all economic interactions in the model also involve foreign agents that exchange goods and services with domestic agents through international trade. The model includes different production sectors and goods markets and also has a government budget constraint that allows it to capture government expenditure in different sectors. In the model, government expenditure is financed through the collection of taxes from firms and households and from import duties. In the model, events are evaluated as 'shocks' to the system. The initial baseline solution reflects a scenario that represents the state of a country's economy in the absence of a specific shock. Then the model is 'shocked' to reflect the new state of the world (e.g. the outbreak of a global pandemic) and the new equilibrium represents a 'what-if' scenario. The comparison between this scenario and the pre-shock baseline at any given point in time represents the impact of the event, for instance in terms of the effect on overall economic 
production. In our analysis the simulated shocks can take various forms in order to reflect the impacts of COVID-19, but we focus mainly on the effects on sectorial demand caused by physical distancing measures (e.g. social distancing regulations, but also individual behaviour to avoid containing the virus) in different contact-intensive sectors.

The underlying economic data used for the purpose of our analyses are taken from the Global Trade Analysis Project (GTAP) database. This database has been developed and continuously updated by the Centre for Global Trade Analysis at Purdue University since 1993. Overall, GTAP covers 140 countries and 57 GTAP commodities, and includes all bilateral trade patterns, production, consumption and intermediate inputs of commodities and services. For this report we have used GTAP version 10a. From the GTAP database, we extracted a Social Accounting Matrix (SAM) for the specific countries and regions included in the analysis. The SAM is a complex table expressed in terms of incomes and expenditures, (i.e. a double entry accounting method). GTAP includes SAMs for individual countries, which are based on national accounts data (e.g. use-supply tables, input-output tables), information from household survey data and trade data. GTAP collects and coordinates country SAMs from researchers across the world and cleans and standardises the data. Table A.1 lists the countries and regions included in the analysis: the US, UK, EU-27, China, other high-income countries, middle-income countries and lowincome countries. 
Table A.1. Countries and regions included in the analysis

\begin{tabular}{|c|c|c|}
\hline $\begin{array}{l}\text { Country/ } \\
\text { region }\end{array}$ & Countries & GTAP country code \\
\hline USA & United States & usa \\
\hline UK & United Kingdom & gbr \\
\hline EU-27 & $\begin{array}{l}\text { Austria, Belgium, Bulgaria, Croatia, Cyprus, Czech } \\
\text { Republic, Denmark, Estonia, Finland, France, } \\
\text { Germany, Greece, Hungary, Ireland, Italy, Latvia, } \\
\text { Lithuania, Luxembourg, Malta, Netherlands, Poland, } \\
\text { Portugal, Romania, Slovakia, Slovenia, Spain, Sweden }\end{array}$ & $\begin{array}{l}\text { aut, bel, bgr, hrv, cyp, cze, dnk, } \\
\text { est, fin, fra, deu, grc, hun, irl, ita, } \\
\text { lva, Itu, lux, mlt, nld, pol, prt, rou, } \\
\text { svk, svn, esp, swe }\end{array}$ \\
\hline China & China & chn \\
\hline India & India & ind \\
\hline Russia & Russian Federation & rus \\
\hline High income & $\begin{array}{l}\text { Australia, New Zealand, Rest of Oceania, Hong Kong, } \\
\text { Japan, Korea, Taiwan, Brunei Darussalam, Indonesia, } \\
\text { Malaysia, Singapore, Canada, Mexico, Rest of North } \\
\text { America, Brazil, Chile, Colombia, Uruguay, Costa } \\
\text { Rica, Panama, Puerto Rico, Trinidad and Tobago, } \\
\text { Switzerland, Liechtenstein, EFTA, Bahrain, Israel, } \\
\text { Kuwait, Oman, Qatar, Saudi Arabia, Turkey, United } \\
\text { Arab Emirates, Mauritius, South Africa }\end{array}$ & $\begin{array}{l}\text { aus, nzl, xoc, hkg, jpn, kor, twn, } \\
\text { brn, mys, sgp, tha, can, mex, xna, } \\
\text { arg, bra, chl, col, ecu, pry, per, ury, } \\
\text { cri, gtm, pan, dom, jam, pri, tto, } \\
\text { che, nor, xef, alb, blr, rus, xee, xer, } \\
\text { kaz, arm, aze, geo, bhr, irn, isr, jor, } \\
\text { kwt, omn, qat, sau, tur, are, mus, } \\
\text { bwa, nam, zaf, xtw. }\end{array}$ \\
\hline $\begin{array}{l}\text { Middle } \\
\text { income }\end{array}$ & $\begin{array}{l}\text { Thailand, Argentina, Ecuador, Paraguay, Peru, } \\
\text { Venezuela, Guatemala, Dominican Republic, Jamaica, } \\
\text { Caribbean, Albania, Belarus, Ukraine, Rest of Eastern } \\
\text { Europe, Rest of Europe, Kazakhstan, Armenia, } \\
\text { Azerbaijan, Georgia, Iran, Jordan, Botswana, Namibia, } \\
\text { Rest of the World }\end{array}$ & $\begin{array}{l}\text { tha, arg, ecu, pry, per, ven, gtm, } \\
\text { dom, jam, xcb, alb, blr, ukr, xee, } \\
\text { xer, kaz, arm, aze, geo, irn, jor, } \\
\text { bwa, nam, xtw }\end{array}$ \\
\hline Low income & $\begin{array}{l}\text { Mongolia, Rest of East Asia, Cambodia, Lao People's } \\
\text { Democratic Republic, Philippines, Viet Nam, Rest } \\
\text { of Southeast Asia, Bangladesh, Nepal, Pakistan, Sri } \\
\text { Lanka, Rest of South Asia, Bolivia, Rest of South } \\
\text { America, Honduras, Nicaragua, El Salvador, Rest } \\
\text { of Central America, Kyrgyzstan, Tajikistan, Rest of } \\
\text { Former Soviet Union, Rest of Western Asia, Egypt, } \\
\text { Morocco, Tunisia, Rest of North Africa, Benin, } \\
\text { Burkina Faso, Cameroon, Cote d'Ivoire, Ghana, } \\
\text { Guinea, Nigeria, Senegal, Togo, Rest of Western } \\
\text { Africa, Central Africa, South Central Africa, Ethiopia, } \\
\text { Kenya, Madagascar, Malawi, Mozambique, Rwanda, } \\
\text { Tanzania, Uganda, Zambia, Zimbabwe, Rest of } \\
\text { Eastern Africa, Rest of South African Customs }\end{array}$ & $\begin{array}{l}\text { Mng, xea, khm, lao, phl, vnm, xse, } \\
\text { bgd, npl, pak, Ika, xsa, bol, xsm, } \\
\text { hnd, nic, slv, xca, kgz, tjk, xsu, } \\
\text { xws, egy, mar, tun, xnf, ben, bfa, } \\
\text { cmr, civ, gha, gin, nga, sen, tgo, } \\
\text { xwf, xcf, xac, eth, ken, mdg, mwi, } \\
\text { moz, rwa, tza, uga, zmb, zwe, } \\
\text { xec, xsc }\end{array}$ \\
\hline
\end{tabular}

Note: The GTAP country codes are broadly based on the United Nations ISO 3-digit country code system.

For reasons of parsimony we aggregated the 57 GTAP commodities into 8 broader sectors: agriculture and manufacturing, hospitality, retail and wholesale, transportation, recreation, health and social care, education, and other services (Table A.2). As explained in the following section, 
we mainly focused on demand-effects in the service sectors that are most negatively hit by COVID-19 due to their reliance on close physical interactions.

\section{Table A.2. GTAP sectors included in the analysis}

\begin{tabular}{|l|l|}
\hline Sector & GTAP code \\
\hline Agriculture and manufacturing & $\begin{array}{l}\text { pdr, whr, gro, v_f, osd, c_b, pfb, ocr, ctl, oap, } \\
\text { rmk, wol, frs, fsh, coa, oil, gas, oxt, cmt, omt, } \\
\text { vol, mil, pcr, sgr, ofd, b_t, tex, wap, lea, lum, } \\
\text { ppp, p_c, chm, bph, rpp, nmm, i_s, nfm, fmp, } \\
\text { ele, eeq, ome, mvh, otn, omf, ely, gdt, wtr. }\end{array}$ \\
\hline Hospitality (accommodation and food) & afs \\
\hline Recreation & ros \\
\hline Retail and wholesale & trd \\
\hline Transportation (air travel, water and other transport) & otp, wtp, atp \\
\hline Health and social care (human health and social work) & hht \\
\hline Education & edu \\
\hline $\begin{array}{l}\text { Other services (construction, warehousing, } \\
\text { communication, financial services, insurance, real estate, } \\
\text { business services, public administration, dwellings) }\end{array}$ & cns, whs, cmn, ofi, ins, rsa, obs, dwe \\
\hline
\end{tabular}

\section{A.2. The impact of COVID-related shocks on contact-intensive service sectors}

\section{A.2.1. Model implementation}

For the purpose of this analysis we modelled a post-lockdown and pre-vaccine economy where full closures of sectors are lifted but economic actors such as firms and households are faced with higher transaction costs, especially when purchasing goods or services from providers in sectors that require close physical interaction. Transaction costs can be of monetary form but also related to increased levels of inconvenience or extra time necessary to make an economic transaction. For instance, the relative increase in transaction costs for firms is driven by additional cost associated with stricter regulations to make venues clean and/or safe (e.g. regulations that restrict the number of people at a venue at any given time). We assumed an increase in transaction costs due to COVID-19 in the following sectors: hospitality, recreation, retail and wholesale, transport, recreation, and health.

Within the model we capture the increase in transaction costs though a 'virtual tax' on consumption on these sectors' outputs. The 'virtual tax' raises the relative prices that households and firms face when purchasing final or intermediate goods and services, as they are faced with higher transaction costs. The rise in the relative price of the service, all else equal, reduces the overall quantity of the good or service in the specific sector exchanged. In the model, transaction costs do not directly increase the monetary price of the good or service, and hence do not 
generate revenue for the government like a normal tax, but in our model goes to a special 'waste' account. The 'virtual tax' is applied to domestically produced goods and services, as well as to imported goods and services, in the hospitality, recreation, retail and wholesale, transportation, and health sectors.

Because of the general equilibrium nature of the model, this implied change in price could also make production in other sectors, e.g. manufacturing or agriculture, more expensive, and hence has direct negative ripple effects on other parts of the economy as well. Furthermore, the relative price increases in some of these sectors redirects some demand towards consumption of other goods or services. This results in a reallocation of household demand across sectors, with total expenditure levels driven by the size of the shocks and the relative change in the price in the affected sectors. Overall, higher relative prices of a given good or services also reduces the disposable income of households, all else being equal, which also has an indirect negative effect on the overall quantity of goods or services trade in the equilibrium.

Technically, for each country i, we derived the implied average rise in price (gross of the 'virtual tax') in sector $s$ using the sector-specific demand price elasticity $\varepsilon_{s}$ and the assumed change in sector-specific demand $q_{s, i}$ as follows:

$$
\frac{\Delta p_{s, i}}{p_{s, i}}=\frac{\frac{\Delta q_{s, i}}{q_{s, i}}}{\varepsilon_{s}}(1)
$$

Note that in the analysis, across different scenarios on which countries can immunise their populations, we adjust for the level of imported (exported) services that come (or go) from (to) countries still negatively affected by COVID-19. For that purpose, equation (1) is adjusted to include the weight of trade (final and intermediate inputs) from those countries with and without access to a vaccine (see equation (2)). The more countries as a group are having access to a vaccine, the smaller the imported (exported) relative increase in transaction costs becomes. $\theta$ represents the weight of trade from countries without a vaccine, which we obtain from the GTAP 10a SAM data:

$$
\frac{\Delta p_{s, i}}{p_{s, i}}=\frac{\frac{\Delta q_{s, i}}{q_{s, i}}}{\varepsilon_{s}} \cdot \theta
$$

\section{A.2.2. Calibrating the sectorial shocks}

In order to calibrate a post-lockdown and pre-vaccine economy we drew on existing data for the sector-specific demand changes $\left(\Delta q_{s}\right)$ and estimates from the existing literature for price elasticities $\left(\varepsilon_{s}\right)$.

\section{Calibrating $\Delta q_{S}$}

To calibrate the magnitude of the shock $\Delta q_{s, i}$, we draw on a set of different real-world data to get a sense of the order of magnitude on how much the value of production in specific service sectors dropped due to the COVID-19 outbreak in the absence of drastic lockdown measures. First, we use economic activity data from Sweden for the following sectors: hospitality; recreation; transportation; trade and wholesale; and health and social care. Sweden reflects a country that had 
not introduced as drastic lockdown measures as many other countries and therefore represents a base case example of how a post-lockdown, pre-vaccine economy might look, in which at least some regulations are in place and people are still exercising a certain level of aversion behaviour in order not to contract the virus. Second, we use Google Community Mobility data to adjust the economic activity values for Sweden and make them region- or country-specific.

\section{Swedish production value data}

We used the seasonally adjusted Swedish sectorial production value index, ${ }^{23}$ because Sweden was one of the countries globally that did not introduce drastic lockdown measures to quarantine large parts of the population, instead mostly appealing to citizens to be vigilant and responsible.

Based on data from Sweden, we get a sense of how sectorial activity can be impaired even in the absence of large-scale lockdown orders and business closures.

The first Swedish COVID-19 case was confirmed on 31 January in a woman who returned to Sweden from Wuhan, but the individual was immediately isolated, and the disease did not spread further (Folkhälsomyndigheten 2020a). By 27 February six more cases had been confirmed, mostly related to travellers returning from Italy. Through January and February, and up until early March, excess deaths evolved normally as would have been expected in a regular flu season. Google searches for search terms such as 'fever', 'cough' or 'sick' only started to be above average from the middle of February (Andersen et al. 2020). The first cases of community transmission were confirmed at the beginning of March and the first official death related to COVID-19 was recorded on 11 March, the day the WHO declared the COVID-19 outbreak a global pandemic (Folkhälsomyndigheten 2020b). The Swedish government advised its citizens for the first time to stay home if they were feeling sick on 10 March, one day before neighbouring Denmark went into lockdown. Following the first fatality, the Swedish Public Health Agency recommended that people over the age of 70 should limit close contract with others and avoid busy public places. It also recommended that employees should work from home if possible, and that secondary schools and universities (for children aged 16 and above) should close and introduce online learning. The Swedish government also recommended that people should not travel abroad or journey extensively within the country. In the middle of March the government announced a ban on gatherings of more than 500 people, and then reduced this figure to 50 by the end of March 2020.24 Instead of employing large-scale lockdown measures, the Swedish government relied on mostly voluntary measures (Milne 2020a). Further evidence suggests that, despite the lack of mandatory lockdowns, people in Sweden followed a level of aversion behaviour to avoid contracting the virus (Andersen et al. 2020). For instance, compared to Denmark, which introduced relatively stringent mandatory lockdown measures, household consumption in Sweden dropped by almost the same magnitude (29 per cent in Denmark compared to 25 per cent in Sweden), implying that most of the economic contraction in sectors affected by close cinema and concerts, religious meetings, demonstrations, lectures, competitive sports, amusement parks, fairs and markets, but not including gatherings in schools, workplaces, public transport, grocery stores or shopping malls, health clubs or private events (Krisinformation 2020). 
physical interactions might be caused by the avoidance behaviour of individuals independent of strict government mandates to physically distance.

Table A.3. reports the year-on-year changes in the seasonally adjusted Swedish sectorial production value index at constant prices for the months November 2020 through August $2020 .{ }^{25}$ It shows that for sectors that are associated with relatively high levels of close personal interaction, the production index decreased dramatically in March, compared to the previous months (November to February). For instance, the production value of hotels and restaurants dropped in March 2020 by 31.6 per cent compared to March of the previous year, and it decreased even further in April. May and June and by August is still about 24 per cent lower. The production value of the transport sector dropped by almost 11 per cent compared to the previous year in March, and in August was still about 15 per cent lower than in the same month a year before. The arts, entertainment and recreation sector dropped by almost 12 per cent in March compared to the previous year, even though for most of March Sweden did not yet have a ban on mass gatherings below 5,000 people. The production value of the arts, entertainment and recreation sector dropped further in April, only to recover again in May, June, and July but it was still almost 18 per cent below the value in the previous year by August 2020. The retail and wholesale sector production value dropped by about 2 per cent in March compared to the previous year, though it was higher in January and February, which could be explained by individuals anticipating potential lockdowns and purchasing certain goods, but it is not possible to confirm this with the data available. By August, the production value was still about 5.4 per cent below its value in August of the previous year. The health and social care sector reported a 1.4 per cent drop in March, and by August it was still about 6 per cent below the value observed in 2019. Other sectors, such as mining and manufacturing, did not experience an immediate drop in March, but only later in April and the following months. The drop in production in the manufacturing sectors could be driven not only by conditions in Sweden but also by difficulties sourcing intermediate goods through global supply chains interrupted due to the COVID-19 outbreak (Milne 2020b). 
Table A.3. Sweden's production value index by sector, year-on-year changes by month

\begin{tabular}{|c|c|c|c|c|c|c|c|c|c|c|}
\hline NAICS & Nov & Dec & Jan & Feb & Mar & Apr & May & June & July & Aug \\
\hline $\begin{array}{l}\text { B-D: mining, } \\
\text { quarrying, } \\
\text { manufacturing } \\
\text { and energy }\end{array}$ & $1.4 \%$ & $-1.9 \%$ & $0.4 \%$ & $0.9 \%$ & $0.8 \%$ & $-14.5 \%$ & $-14.7 \%$ & $-10.0 \%$ & $-6.5 \%$ & $-0.5 \%$ \\
\hline $\begin{array}{l}\text { E: water works; } \\
\text { sewage plants, } \\
\text { waste-disposal } \\
\text { plants }\end{array}$ & $6.1 \%$ & $4.9 \%$ & $17.7 \%$ & $-6.1 \%$ & $5.6 \%$ & $-3.6 \%$ & $-4.4 \%$ & $-0.9 \%$ & $1.4 \%$ & $2.1 \%$ \\
\hline $\begin{array}{l}\text { G: Retail; } \\
\text { wholesale }\end{array}$ & $2.1 \%$ & $2.2 \%$ & $2.3 \%$ & $3.6 \%$ & $-2.0 \%$ & $-13.2 \%$ & $-10.1 \%$ & $-6.0 \%$ & $-1.7 \%$ & $-5.4 \%$ \\
\hline $\mathrm{H}$ : transport & $-2.5 \%$ & $-1.6 \%$ & $-0.9 \%$ & $-2.4 \%$ & $-10.7 \%$ & $-19.4 \%$ & $-21.9 \%$ & $-21.7 \%$ & $-17.4 \%$ & $-14.9 \%$ \\
\hline $\begin{array}{l}\text { I: hotels and } \\
\text { restaurants }\end{array}$ & $0.0 \%$ & $-1.6 \%$ & $2.8 \%$ & $3.8 \%$ & $-31.7 \%$ & $-42.1 \%$ & $-53.2 \%$ & $-41.7 \%$ & $-16.4 \%$ & $-23.6 \%$ \\
\hline $\begin{array}{l}\mathrm{J}: \text { information } \\
\text { and } \\
\text { communication } \\
\text { companies }\end{array}$ & $3.8 \%$ & $-5.5 \%$ & $3.3 \%$ & $2.3 \%$ & $-2.6 \%$ & $-1.1 \%$ & $-0.8 \%$ & $0.3 \%$ & $1.6 \%$ & $-5.6 \%$ \\
\hline $\begin{array}{l}\text { L: real estate } \\
\text { companies }\end{array}$ & $1.6 \%$ & $3.1 \%$ & $7.8 \%$ & $3.0 \%$ & $2.7 \%$ & $1.9 \%$ & $0.2 \%$ & $1.1 \%$ & $1.4 \%$ & $1.4 \%$ \\
\hline $\begin{array}{l}\mathrm{M}+\mathrm{N} \text { : } \\
\text { professional, } \\
\text { scientific and } \\
\text { administrative } \\
\text { services }\end{array}$ & $-2.4 \%$ & $-0.3 \%$ & $-2.4 \%$ & $-2.3 \%$ & $-2.4 \%$ & $-8.7 \%$ & $-12.7 \%$ & $-12.5 \%$ & $-7.5 \%$ & $-4.2 \%$ \\
\hline $\begin{array}{l}\text { P: educational } \\
\text { establishments }\end{array}$ & $9.2 \%$ & $4.8 \%$ & $8.2 \%$ & $2.6 \%$ & $-1.3 \%$ & $-2.8 \%$ & $-1.9 \%$ & $-3.7 \%$ & $3.8 \%$ & $4.7 \%$ \\
\hline $\begin{array}{l}\text { Q: human } \\
\text { health and } \\
\text { social work } \\
\text { establishments }\end{array}$ & $-1.2 \%$ & $-1.4 \%$ & $2.9 \%$ & $4.8 \%$ & $-1.4 \%$ & $-8.2 \%$ & $-8.0 \%$ & $-7.6 \%$ & $-2.0 \%$ & $-6.0 \%$ \\
\hline $\begin{array}{l}\mathrm{R}+\mathrm{S} \text { : art, } \\
\text { entertainment, } \\
\text { recreation }\end{array}$ & $-0.4 \%$ & $3.8 \%$ & $7.2 \%$ & $9.7 \%$ & $-11.5 \%$ & $-19.8 \%$ & $-9.3 \%$ & $-10.0 \%$ & $-5.2 \%$ & $-17.9 \%$ \\
\hline
\end{tabular}

Source: Swedish seasonally adjusted sector-specific production value index with constant prices (Statistics Sweden 2020). Note: Table entries represent year-on-year changes, comparing the values by month in 2020 to equivalent values in 2019 .

While data from Sweden provides a sense of how economic activity in the five contact-intensive sectors is affected by COVID-19, we assume in our analysis that they reflect an upper-bound estimate as at the time the wearing of masks wasn't compulsory in many places (and is still not in Sweden) and many countries have also improved their track and trace systems, allowing economic activity in some of these sectors to potentially recover. In order to be conservative in 
our assumptions we assume a base case value $(M)$ change in $\Delta q_{s}$ of 50 per cent of the average change in the Swedish production value over the months March to August. To add sensitivity, we vary the level of impact around the baseline value. For the higher value $(H)$ change we assume 75 per cent of the average change in Swedish production value over the same time period and for the lower value $(L)$ change in sectorial economic activity we assume 25 per cent. Table A.4 reports the assumed changes by sector:

Table A.4. Assumed changes in $\Delta q_{s}$

\begin{tabular}{|l|c|c|c|}
\hline & \multicolumn{3}{|c|}{$\Delta q_{S}$} \\
\hline Hospitality & M & L & H \\
\hline Recreation & $-17.4 \%$ & $-8.7 \%$ & $-26.1 \%$ \\
\hline Retail and wholesale & $-3.2 \%$ & $-1.6 \%$ & $-4.8 \%$ \\
\hline Transportation & $-8.8 \%$ & $-4.4 \%$ & $-13.2 \%$ \\
\hline Health and social care & $-6.1 \%$ & $-3.1 \%$ & $-9.2 \%$ \\
\hline
\end{tabular}

Note: Derived from taking the average value over the months March to August as reported in Table A.3 and multiplying by $0.5(\mathrm{M}) ; 0.25(\mathrm{~L})$; and $0.75(\mathrm{H})$ respectively.

\section{Google Community Mobility data}

As changes in economic activity across the five different contact-intensive service sectors in other countries or regions are most likely to some extent different than the changes we observe in Sweden, we used Google Community Mobility data (Google 2020) to make the assumed base value for $\Delta q_{s}$ country- or region-specific. The mobility data provides information on movement trends over time by geography (e.g. country or region) and by different types of places, including retail and recreation, groceries and pharmacies, parks, transit stations, workplaces or residential and we apply this data as a proxy for $q_{s, i} \cdot{ }^{26}$ In essence, we use information from the mobility data $m$ to determine a country-or region-specific adjustment factor $r_{i}$ based on estimating the relative difference in economic activity in a given country or region compared to Sweden (SWE): ${ }^{27} r_{i}=\frac{m_{i}}{m_{S W E}}$ experience the same drop in economic activity as Sweden, which would represent a relative strong assumption. That is, irrespective of different lockdown and quarantine measures across countries over time, even if other countries would have had the identical physical distancing regulations as Sweden, there are other country-specific factors that could determine relative differences, such as culture or different levels of wealth. For instance, if a relatively large part of a country's households is dependent on close physical interaction to provide a livelihood to economically survive, the level of abiding by rules and regulations might differ. 
For most countries available in the dataset, the mobility data is available daily since midFebruary and compares changes in mobility compared to a baseline point in time which is January/February for each year. Comparing unadjusted mobility values would most likely just reflect differences in lockdown measures and physical distancing regulations, as well as other government responses to the COVID-19 pandemic, as Sweden had very different physical distancing orders and rules compared to other countries. We therefore estimate the $r_{i}$ that is adjusted for different levels of the government response to the crisis, or to put differently, we try to estimate the level of mobility in each country or region that would have been observed if it had the same level of government response like Sweden. We therefore complement the mobility data with the government response index provided by Hale et al. (2020). The government response data consists of an index that takes the values between 0 and 100 that records variation in the response of government over time. ${ }^{28}$ It includes measures about the overall stringency of lockdown policies; measures on containment and health (e.g. testing policy and contract tracing, as well as investments in healthcare); economic support (e.g. income support or debt relief). The data set by Hale et al. (2020) also includes the total number of confirmed COVID-19 cases and corresponding dates by country and date and we merge this to the google mobility data which leads to a panel data sample of countries by including daily cases, deaths and the corresponding government response function, as well as observed mobility to different locations.

Using the panel data, we run a series of regression models based on the following three equations:

$$
\begin{aligned}
& c_{i, t}=\delta_{i, 0}+\delta_{i, 1} m_{i, t-1}+\varepsilon_{i, t} \\
& g_{i, t}=\alpha_{i, 0}+\alpha_{i, 1} c_{i, t-1}+\vartheta_{i, t} \\
& m_{i, t}=\beta_{i, 0}+\beta_{i, 1} g_{i, t-1}+\theta_{i, t}
\end{aligned}
$$

where $c_{i, t}$ represents the 7 -day moving average of confirmed COVID-19 cases by country $i$ at day $t, g_{i, t}$ represents the government response index; $m_{i, t}$ represents the observed mobility at any given day $t$ compared to the baseline; $\varepsilon_{i, t}, \vartheta_{i, t}$ and $\theta_{i, t}$ are idiosyncratic error terms. Equation (3) represents the main model of interest, showing the relationship between observed mobility and the strictness of government response. However, there is the issue that the government response is a function of the number of cases observed (equation 2) and the number of cases observed are a function of previous mobility (equation 1 ). For $m_{i, t}$ we use the mobility value for residential locations where a higher value represents less mobility to locations outside the residence (e.g. home), including all types of mobility to recreation, groceries and pharmacies, parks, transit stations, and workplaces. We recode the value so that lower values represent less mobility to outside the residence (e.g. home). In the final sample we have 181 countries included, but China is missing as no mobility data is available, resulting in an overall number of observations of 23,482 .

For each country separately we run the three equations using the 7-day lags of the explanatory variables and obtain estimated parameters $\hat{\delta}_{i, 0} ; \hat{\delta}_{i, 1} ; \hat{\alpha}_{i, 0} ; \hat{\alpha}_{i, 1} ; \hat{\beta}_{i, 0}$; and $\hat{\beta}_{i, 1}$. Based on these 
parameters we then try to estimate the levels of mobility that would have occurred in each country if they would have had similar government response like Sweden. To that end we plug equation (1) into equation (2):

$$
\hat{g}_{i, t}=\hat{\alpha}_{i, 0}+\hat{\alpha}_{i, 1}\left(\hat{\delta}_{i, 0}+\hat{\delta}_{i, 1} m_{i, t-2}\right)
$$

and subsequently plug equation (4) into equation (3) to obtain:

$$
\hat{m}_{i, t}=\hat{\beta}_{i, 0}+\hat{\beta}_{i, 1}\left(\left(\hat{\alpha}_{i, 0}+\hat{\alpha}_{i, 1}\left(\hat{\delta}_{0}+\hat{\delta}_{1} m_{i, t-3}\right)\right)\right.
$$

To get the level of predicted mobility by country if the same government policy response as in Sweden (SWE) would have been applied, we calculate the following:

$$
\hat{m}_{i, t}{ }^{*}=\hat{\beta}_{i, 0}+\hat{\beta}_{i, 1}\left(\left(\hat{\alpha}_{i, 0}+\hat{\alpha}_{i, 1}{ }^{S W E}\left(\hat{\delta}_{0}+\hat{\delta}_{1} m_{i, t-3}\right)\right)\right.
$$

The country-or region-specific adjustment factor $r_{i}$ is then calculated as $\hat{r}_{i}=\frac{\widehat{m}_{i}{ }^{*}}{\widehat{m}_{S W E}}$. The resulting estimated adjustment factors by country or region are reported in Table A.5.

Table A.5. Estimated country- or region-specific adjustment parameter

\begin{tabular}{|l|c|}
\hline Country/Region & $\hat{r}_{i}$ \\
\hline EU-27 & $5.6 \%$ \\
\hline High & $-4.1 \%$ \\
\hline India & $3.8 \%$ \\
\hline Low & $0.5 \%$ \\
\hline Middle & $-4.8 \%$ \\
\hline Russia & $7.0 \%$ \\
\hline UK & $-5.3 \%$ \\
\hline USA & $-6.6 \%$ \\
\hline
\end{tabular}

The estimates reported in Table A.5 suggest that for instance adjusted mobility in the EU-27 would have been about 5.6 per cent larger than the one in Sweden, with similar government responses between the two. Mobility in high-income countries would have been about 4.1 percent lower than in Sweden and mobility in India about 3.8 per cent higher than in Sweden. Due to lack of mobility data, we do not have the adjustment factor for China, but for simplicity we assume that China would have had the same adjustment factor as Russia. We use the estimates for $r_{i}$ and apply them to the values for $\Delta q_{s}$ reported in Table A.4 as: $\Delta q_{s, i}=\left(1-\hat{r}_{i}\right) * \Delta q_{s}$. The assumed country- or region-specific values by sector are reported in Table A.6. ${ }^{29}$ 
Table A.6. Assumed country- or region-specific changes in $\Delta q_{s, i}$

\begin{tabular}{|c|c|c|c|c|c|}
\hline & Hospitality & Recreation & $\begin{array}{l}\text { Retail and } \\
\text { wholesale }\end{array}$ & Transportation & $\begin{array}{l}\text { Health and } \\
\text { social care }\end{array}$ \\
\hline \multicolumn{6}{|c|}{ M: base case value assumption } \\
\hline USA & $-18.5 \%$ & $-6.5 \%$ & $-3.4 \%$ & $-9.4 \%$ & $-2.9 \%$ \\
\hline UK & $-18.3 \%$ & $-6.5 \%$ & $-3.4 \%$ & $-9.3 \%$ & $-2.9 \%$ \\
\hline China & $-16.2 \%$ & $-5.7 \%$ & $-3.0 \%$ & $-8.2 \%$ & $-2.6 \%$ \\
\hline EU-27 & $-16.4 \%$ & $-5.8 \%$ & $-3.0 \%$ & $-8.3 \%$ & $-2.6 \%$ \\
\hline High & $-18.1 \%$ & $-6.4 \%$ & $-3.3 \%$ & $-9.2 \%$ & $-2.9 \%$ \\
\hline India & $-16.7 \%$ & $-5.9 \%$ & $-3.1 \%$ & $-8.5 \%$ & $-2.7 \%$ \\
\hline Russia & $-16.2 \%$ & $-5.7 \%$ & $-3.0 \%$ & $-8.2 \%$ & $-2.6 \%$ \\
\hline Medium & $-18.2 \%$ & $-6.4 \%$ & $-3.4 \%$ & $-9.2 \%$ & $-2.9 \%$ \\
\hline Low & $-17.3 \%$ & $-6.1 \%$ & $-3.2 \%$ & $-8.8 \%$ & $-2.7 \%$ \\
\hline \multicolumn{6}{|c|}{ L: lower value assumption } \\
\hline USA & $-9.3 \%$ & $-3.3 \%$ & $-1.7 \%$ & $-4.7 \%$ & $-1.5 \%$ \\
\hline UK & $-9.2 \%$ & $-3.2 \%$ & $-1.7 \%$ & $-4.6 \%$ & $-1.5 \%$ \\
\hline China & $-8.1 \%$ & $-2.9 \%$ & $-1.5 \%$ & $-4.1 \%$ & $-1.3 \%$ \\
\hline EU-27 & $-8.2 \%$ & $-2.9 \%$ & $-1.5 \%$ & $-4.2 \%$ & $-1.3 \%$ \\
\hline High & $-9.1 \%$ & $-3.2 \%$ & $-1.7 \%$ & $-4.6 \%$ & $-1.4 \%$ \\
\hline India & $-8.4 \%$ & $-3.0 \%$ & $-1.5 \%$ & $-4.2 \%$ & $-1.3 \%$ \\
\hline Russia & $-8.1 \%$ & $-2.9 \%$ & $-1.5 \%$ & $-4.1 \%$ & $-1.3 \%$ \\
\hline Medium & $-9.1 \%$ & $-3.2 \%$ & $-1.7 \%$ & $-4.6 \%$ & $-1.4 \%$ \\
\hline Low & $-8.6 \%$ & $-3.1 \%$ & $-1.6 \%$ & $-4.4 \%$ & $-1.4 \%$ \\
\hline \multicolumn{6}{|c|}{$\mathrm{H}$ : higher value assumption } \\
\hline USA & $-27.8 \%$ & $-9.8 \%$ & $-5.1 \%$ & $-14.1 \%$ & $-4.4 \%$ \\
\hline UK & $-27.5 \%$ & $-9.7 \%$ & $-5.1 \%$ & $-13.9 \%$ & $-4.4 \%$ \\
\hline China & $-24.3 \%$ & $-8.6 \%$ & $-4.5 \%$ & $-12.3 \%$ & $-3.9 \%$ \\
\hline EU-27 & $-24.6 \%$ & $-8.7 \%$ & $-4.5 \%$ & $-12.5 \%$ & $-3.9 \%$ \\
\hline High & $-27.2 \%$ & $-9.6 \%$ & $-5.0 \%$ & $-13.8 \%$ & $-4.3 \%$ \\
\hline India & $-25.1 \%$ & $-8.9 \%$ & $-4.6 \%$ & $-12.7 \%$ & $-4.0 \%$ \\
\hline Russia & $-24.3 \%$ & $-8.6 \%$ & $-4.5 \%$ & $-12.3 \%$ & $-3.9 \%$ \\
\hline Medium & $-27.3 \%$ & $-9.6 \%$ & $-5.0 \%$ & $-13.9 \%$ & $-4.3 \%$ \\
\hline Low & $-25.9 \%$ & $-9.2 \%$ & $-4.8 \%$ & $-13.2 \%$ & $-4.1 \%$ \\
\hline
\end{tabular}




\section{Calibrating $\varepsilon_{S}$}

To calibrate the other parameter in equation (1), we looked to the literature for demand price elasticities $\left(\varepsilon_{s}\right) .{ }^{30}$ With regard to the hospitality sector, there is no specific elasticity estimate for food services such as restaurants, but estimates are available from specific tourism subsectors such as accommodation, where the demand price elasticity has been estimated to be -0.727 using a meta-regression analysis (Peng et al. 2015). The demand price elasticity for the recreation sector has been estimated to be -0.158 after taking into account study heterogeneity and publication bias (Rosenberger \& Stanley 2010). The average price elasticity for recreation based on a meta-analysis of 120 studies was -0.928 but reduces substantially by taking into account publication bias. The demand price elasticity for transportation depends strongly on the mode of transport. For car travel, the elasticity is estimated to be between - 0.1 to -0.5 (Dunkerley et al. 2014). Based on a meta-analysis consisting of more than 200 empirical studies, the mean price elasticity of air travel demand is about -1.15 with a standard deviation 0.619 (Brons et al. 2002). The total passenger transport demand price elasticity, independent of transport mode, has been estimated to be - 0.6 (Fouquet 2012). The demand price elasticity for the GTAP sector 'retail and wholesale' has been estimated to be -1.2 (Reimer \& Hertel 2004). Lastly, the demand price elasticity for the health sector has been estimated to be about -0.17 (Ringel et al. 2002).

Table A.7 summarises the parameter value assumptions used for the model parameters $\varepsilon_{s,}$ with $M$ representing the base case value assumption for the elasticity and $L$ and $H$ representing the lower and higher value parameter assumption respectively. For hospitality, retail and wholesale and health and social care, we use the identified values from the literature above but add a 50 per cent lower or higher value as the lower and upper bound values for the simulations. For transportation we apply the upper and lower bound values already identified in the extensive literature. For recreation we use the value -0.158 as the lower bound value and add 50 per cent each to get the middle value and the upper bound value.

Table A.7. Parameter value assumptions for sector-specific elasticities

\begin{tabular}{|l|c|c|c|}
\hline \multicolumn{1}{|c|}{ Sector } & \multicolumn{2}{c|}{ Elasticity $\varepsilon_{s}$} \\
\hline Hospitality & $M$ & $L$ & $H$ \\
\hline Retail and wholesale & -0.73 & -0.35 & -1.05 \\
\hline Transportation & -1.20 & -0.60 & -1.80 \\
\hline Recreation & -0.60 & -0.10 & -1.10 \\
\hline Health and social care & -0.24 & -0.16 & -0.36 \\
\hline
\end{tabular}

Note: Author's assumptions about input parameter values for $\varepsilon_{s}$. 'M' represents the base case value assumption; ' $L$ ' represents the lower value assumption and ' $H$ ' represents the higher value assumption of the parameter values. households allocate their income to different goods based on changes in their income levels. That is, in the model, changes in income will also indirectly have effects on overall consumption. In equation (1) we model the direct impact on relative price levels due to increased transaction costs. 


\section{A.3. Limitations of the modelling approach}

The application of a CGE modelling framework to assess the economic implications of inequitable access to COVID-19 vaccines across countries has several strengths, such as the ability to consider the interdependencies between different sectors domestically but also through international trade. However, there are some limitations to the modelling approach taken.

Firstly, the CGE model analysis is not intended to provide an exact forecast of the economy at a given point in time in the future. The deterministic model does not consider transitory (stochastic) short-term changes to the overall economic growth path. The aim of the applied modelling framework is to examine the effects of relative changes across different modelling parameters representing different scenarios and then to compare how the economy of a country would change relative to the baseline, holding all other factors constant. This is a simplification of how events would affect the economy in reality; however, it allows the analysis of specific factors in isolation (in our analysis the sub-optimal performance of contact-intensive sectors).

Secondly, the scenario analysis presented in this report depends heavily on assumptions and parameter value inputs from sources outside of the model. This is common in the CGE modelling approach (e.g. see Maliszewska et al. 2020), but it has to be highlighted as a limitation. For instance, the shock on contact-intensive sectors is calibrated on input data from Sweden and then applied to all countries or regions in the analysis. This implicitly assumes that the shock is of similar relative magnitude across the world, but there is great uncertainty over this. However, in the absence of more available empirical data it is difficult to assess the full validity of this assumption. Furthermore, by using the Swedish production value index to calibrate a demand-shock we assume that most of the shock is caused from the demand-side, but the reduction could also be due to establishments closing due to health concerns, which would represent a supply-shock. The reduction in overall demand could also be due to households adjusting their beliefs about the future and altering their consumption behavior because they expect less income in the future. To address some of the uncertainties around the parameter assumptions made, we ran sensitivity analysis using MonteCarlo simulations, which assumes a stochastic distribution about the parameter inputs and subsequently a range of output values with corresponding confidence intervals. In the future it will be possible to amend some assumptions using better empirical evidence that may emerge.

Thirdly, the CGE modelling framework is based on a micro-foundation of the underlying equations that determine the economic behavior of the various economic agents. However, some of the microeconomic parameters are fixed and are therefore invariant across different scenarios. Such fixed input parameters include, among others, different demand, substitution (own-price and cross-sector) and income elasticities, as well as parameters relevant to production technology, such as the relative importance of each of the production inputs. There are very good reasons to assume that a massive global issue such as the COVID-19 pandemic could represent a tipping point with long-lasting effects on an economy, for instance by changing the economic behavior of households (e.g. changes in consumption patterns and saving rates), or by triggering the development or uptake of new technologies (e.g. more environmentally friendly technologies) or a change in overall government spending patterns (e.g. away from defense to public health spending). However, as it is difficult to assess ex ante whether and how these behavioral changes would evolve, we have kept them fixed in the model. 


\section{Appendix B: Economic effects of inequitable access to COVID-19 vaccines by country (real annual GDP in \$bn)}

Table B.1. Change in real annual GDP in \$bn relative to baseline scenario - EU-27

\begin{tabular}{|c|c|c|c|c|c|c|c|c|c|c|c|c|}
\hline & \multicolumn{3}{|c|}{ Scenario 1} & \multicolumn{3}{|c|}{ Scenario 2} & \multicolumn{3}{|c|}{ Scenario 3} & \multicolumn{3}{|c|}{ Scenario 4} \\
\hline & $\mathbf{M}$ & L & $\mathbf{H}$ & $\mathbf{M}$ & $\mathbf{L}$ & $\mathbf{H}$ & $\mathbf{M}$ & $\mathbf{L}$ & $\mathbf{H}$ & M & $\mathbf{L}$ & $\mathbf{H}$ \\
\hline EU-27 & -983.5 & -404.6 & $-1,885.2$ & -310.6 & -128.8 & -595.9 & -76.3 & -31.2 & -148.5 & -40.3 & -16.5 & -78.1 \\
\hline Austria & -28.1 & -11.6 & -54.0 & -8.9 & -3.7 & -17.1 & -2.2 & -0.9 & -4.3 & -1.2 & -0.5 & -2.2 \\
\hline Belgium & -33.4 & -13.7 & -64.0 & -10.6 & -4.4 & -20.2 & -2.6 & -1.1 & -5.0 & -1.4 & -0.6 & -2.7 \\
\hline Bulgaria & -4.3 & -1.8 & -8.2 & -1.4 & -0.6 & -2.6 & -0.3 & -0.1 & -0.6 & -0.2 & -0.1 & -0.3 \\
\hline Croatia & -3.8 & -1.6 & -7.3 & -1.2 & -0.5 & -2.3 & -0.3 & -0.1 & -0.6 & -0.2 & -0.1 & -0.3 \\
\hline Cyprus & -1.5 & -0.6 & -3.0 & -0.5 & -0.2 & -0.9 & -0.1 & 0.0 & -0.2 & -0.1 & 0.0 & -0.1 \\
\hline Czech Republic & -15.5 & -6.4 & -29.8 & -4.9 & -2.0 & -9.4 & -1.2 & -0.5 & -2.3 & -0.6 & -0.3 & -1.2 \\
\hline Denmark & -22.0 & -9.0 & -42.1 & -6.9 & -2.9 & -13.3 & -1.7 & -0.7 & -3.3 & -0.9 & -0.4 & -1.7 \\
\hline Estonia & -2.0 & -0.8 & -3.8 & -0.6 & -0.3 & -1.2 & -0.2 & -0.1 & -0.3 & -0.1 & 0.0 & -0.2 \\
\hline Finland & -17.0 & -7.0 & -32.5 & -5.4 & -2.2 & -10.3 & -1.3 & -0.5 & -2.6 & -0.7 & -0.3 & -1.3 \\
\hline France & -171.3 & -70.5 & -328.3 & -54.1 & -22.4 & -103.8 & -13.3 & -5.4 & -25.9 & -7.0 & -2.9 & -13.6 \\
\hline Germany & -242.5 & -99.8 & -464.9 & -76.6 & -31.8 & -147.0 & -18.8 & -7.7 & -36.6 & -9.9 & -4.1 & -19.3 \\
\hline Greece & -13.2 & -5.4 & -25.4 & -4.2 & -1.7 & -8.0 & -1.0 & -0.4 & -2.0 & -0.5 & -0.2 & -1.1 \\
\hline Hungary & -10.2 & -4.2 & -19.5 & -3.2 & -1.3 & -6.2 & -0.8 & -0.3 & -1.5 & -0.4 & -0.2 & -0.8 \\
\hline Ireland & -24.5 & -10.1 & -47.0 & -7.7 & -3.2 & -14.9 & -1.9 & -0.8 & -3.7 & -1.0 & -0.4 & -1.9 \\
\hline Italy & -126.2 & -51.9 & -242.0 & -39.9 & -16.5 & -76.5 & -9.8 & -4.0 & -19.1 & -5.2 & -2.1 & -10.0 \\
\hline Latvia & -2.2 & -0.9 & -4.1 & -0.7 & -0.3 & -1.3 & -0.2 & -0.1 & -0.3 & -0.1 & 0.0 & -0.2 \\
\hline Lithuania & -3.4 & -1.4 & -6.6 & -1.1 & -0.4 & -2.1 & -0.3 & -0.1 & -0.5 & -0.1 & -0.1 & -0.3 \\
\hline Luxembourg & -4.5 & -1.8 & -8.6 & -1.4 & -0.6 & -2.7 & -0.3 & -0.1 & -0.7 & -0.2 & -0.1 & -0.4 \\
\hline Malta & -0.9 & -0.4 & -1.8 & -0.3 & -0.1 & -0.6 & -0.1 & 0.0 & -0.1 & 0.0 & 0.0 & -0.1 \\
\hline Netherlands & -57.3 & -23.6 & -109.9 & -18.1 & -7.5 & -34.7 & -4.4 & -1.8 & -8.7 & -2.4 & -1.0 & -4.6 \\
\hline
\end{tabular}




\begin{tabular}{|l|l|l|l|l|l|l|l|l|l|l|l|l|}
\hline & \multicolumn{3}{|c|}{ Scenario 1 } & \multicolumn{7}{c|}{ Scenario 2 } & \multicolumn{3}{l|}{ Scenario 3 } & \multicolumn{3}{l|}{ Scenario 4 } \\
\hline & M & L & H & M & L & H & M & L & H & M & L & H \\
\hline Poland & -37.3 & -15.4 & -71.6 & -11.8 & -4.9 & -22.6 & -2.9 & -1.2 & -5.6 & -1.5 & -0.6 & -3.0 \\
\hline Portugal & -15.0 & -6.2 & -28.7 & -4.7 & -2.0 & -9.1 & -1.2 & -0.5 & -2.3 & -0.6 & -0.3 & -1.2 \\
\hline Romania & -15.8 & -6.5 & -30.2 & -5.0 & -2.1 & -9.6 & -1.2 & -0.5 & -2.4 & -0.6 & -0.3 & -1.3 \\
\hline Slovak Republic & -6.6 & -2.7 & -12.7 & -2.1 & -0.9 & -4.0 & -0.5 & -0.2 & -1.0 & -0.3 & -0.1 & -0.5 \\
\hline Slovenia & -3.4 & -1.4 & -6.5 & -1.1 & -0.4 & -2.1 & -0.3 & -0.1 & -0.5 & -0.1 & -0.1 & -0.3 \\
\hline Spain & -87.9 & -36.2 & -168.6 & -27.8 & -11.5 & -53.3 & -6.8 & -2.8 & -13.3 & -3.6 & -1.5 & -7.0 \\
\hline Sweden & -33.5 & -13.8 & -64.2 & -10.6 & -4.4 & -20.3 & -2.6 & -1.1 & -5.1 & -1.4 & -0.6 & -2.7 \\
\hline
\end{tabular}

Table B.2. Change in real annual GDP in \$bn relative to baseline scenario - High-income countries

\begin{tabular}{|c|c|c|c|c|c|c|c|c|c|c|c|c|}
\hline & \multicolumn{3}{|c|}{ Scenario 1} & \multicolumn{3}{|c|}{ Scenario 2} & \multicolumn{3}{|c|}{ Scenario 3} & \multicolumn{3}{|c|}{ Scenario 4} \\
\hline & M & L & $\mathrm{H}$ & M & $L$ & $\mathrm{H}$ & M & L & $\mathrm{H}$ & M & L & $\mathrm{H}$ \\
\hline High income & -996.9 & -403.9 & $-1,943.4$ & -453.0 & -173.0 & -942.0 & -73.0 & -29.9 & -141.5 & -38.5 & -15.9 & -74.1 \\
\hline Australia & -67.4 & -27.3 & -131.3 & -30.6 & -11.7 & -63.7 & -4.9 & -2.0 & -9.6 & -2.6 & -1.1 & -5.0 \\
\hline Bahrain & -1.9 & -0.8 & -3.6 & -0.8 & -0.3 & -1.8 & -0.1 & -0.1 & -0.3 & -0.1 & 0.0 & -0.1 \\
\hline Brazil & -89.0 & -36.1 & -173.5 & -40.4 & -15.4 & -84.1 & -6.5 & -2.7 & -12.6 & -3.4 & -1.4 & -6.6 \\
\hline Canada & -84.0 & -34.0 & -163.8 & -38.2 & -14.6 & -79.4 & -6.2 & -2.5 & -11.9 & -3.2 & -1.3 & -6.2 \\
\hline Chile & -13.7 & -5.5 & -26.6 & -6.2 & -2.4 & -12.9 & -1.0 & -0.4 & -1.9 & -0.5 & -0.2 & -1.0 \\
\hline Colombia & -15.7 & -6.3 & -30.5 & -7.1 & -2.7 & -14.8 & -1.1 & -0.5 & -2.2 & -0.6 & -0.2 & -1.2 \\
\hline Costa Rica & -3.0 & -1.2 & -5.8 & -1.4 & -0.5 & -2.8 & -0.2 & -0.1 & -0.4 & -0.1 & 0.0 & -0.2 \\
\hline Hong Kong & -17.7 & -7.2 & -34.5 & -8.0 & -3.1 & -16.7 & -1.3 & -0.5 & -2.5 & -0.7 & -0.3 & -1.3 \\
\hline Iceland & -1.2 & -0.5 & -2.3 & -0.5 & -0.2 & -1.1 & -0.1 & 0.0 & -0.2 & 0.0 & 0.0 & -0.1 \\
\hline Indonesia & -54.1 & -21.9 & -105.6 & -24.6 & -9.4 & -51.2 & -4.0 & -1.6 & -7.7 & -2.1 & -0.9 & -4.0 \\
\hline Israel & -19.1 & -7.7 & -37.3 & -8.7 & -3.3 & -18.1 & -1.4 & -0.6 & -2.7 & -0.7 & -0.3 & -1.4 \\
\hline Japan & -245.8 & -99.6 & -479.3 & -111.7 & -42.7 & -232.3 & -18.0 & -7.4 & -34.9 & -9.5 & -3.9 & -18.3 \\
\hline Korea, Rep. & -79.5 & -32.2 & -154.9 & -36.1 & -13.8 & -75.1 & -5.8 & -2.4 & -11.3 & -3.1 & -1.3 & -5.9 \\
\hline Kuwait & -6.5 & -2.6 & -12.7 & -3.0 & -1.1 & -6.2 & -0.5 & -0.2 & -0.9 & -0.3 & -0.1 & -0.5 \\
\hline Malaysia & -17.6 & -7.1 & -34.4 & -8.0 & -3.1 & -16.7 & -1.3 & -0.5 & -2.5 & -0.7 & -0.3 & -1.3 \\
\hline Mexico & -60.9 & -24.7 & -118.7 & -27.7 & -10.6 & -57.5 & -4.5 & -1.8 & -8.6 & -2.4 & -1.0 & -4.5 \\
\hline Monaco & -0.3 & -0.1 & -0.7 & -0.2 & -0.1 & -0.3 & 0.0 & 0.0 & 0.0 & 0.0 & 0.0 & 0.0 \\
\hline
\end{tabular}




\begin{tabular}{|c|c|c|c|c|c|c|c|c|c|c|c|c|}
\hline & \multicolumn{3}{|c|}{ Scenario 1} & \multicolumn{3}{|c|}{ Scenario 2} & \multicolumn{3}{|c|}{ Scenario 3} & \multicolumn{3}{|c|}{ Scenario 4} \\
\hline & M & L & $\mathrm{H}$ & M & L & $\mathrm{H}$ & M & L & $\mathrm{H}$ & M & L & $\mathrm{H}$ \\
\hline $\begin{array}{l}\text { New } \\
\text { Zealand }\end{array}$ & -10.0 & -4.1 & -19.5 & -4.5 & -1.7 & -9.5 & -0.7 & -0.3 & -1.4 & -0.4 & -0.2 & -0.7 \\
\hline Norway & -19.5 & -7.9 & -38.0 & -8.9 & -3.4 & -18.4 & -1.4 & -0.6 & -2.8 & -0.8 & -0.3 & -1.5 \\
\hline Oman & -3.7 & -1.5 & -7.3 & -1.7 & -0.6 & -3.5 & -0.3 & -0.1 & -0.5 & -0.1 & -0.1 & -0.3 \\
\hline Panama & -3.2 & -1.3 & -6.3 & -1.5 & -0.6 & -3.1 & -0.2 & -0.1 & -0.5 & -0.1 & -0.1 & -0.2 \\
\hline Puerto Rico & -5.1 & -2.1 & -9.9 & -2.3 & -0.9 & -4.8 & -0.4 & -0.2 & -0.7 & -0.2 & -0.1 & -0.4 \\
\hline Qatar & -8.9 & -3.6 & -17.3 & -4.0 & -1.5 & -8.4 & -0.6 & -0.3 & -1.3 & -0.3 & -0.1 & -0.7 \\
\hline Saudi Arabia & -38.4 & -15.5 & -74.8 & -17.4 & -6.7 & -36.3 & -2.8 & -1.2 & -5.4 & -1.5 & -0.6 & -2.9 \\
\hline Singapore & -18.0 & -7.3 & -35.1 & -8.2 & -3.1 & -17.0 & -1.3 & -0.5 & -2.6 & -0.7 & -0.3 & -1.3 \\
\hline South Africa & -17.0 & -6.9 & -33.1 & -7.7 & -3.0 & -16.1 & -1.2 & -0.5 & -2.4 & -0.7 & -0.3 & -1.3 \\
\hline Switzerland & -34.0 & -13.8 & -66.3 & -15.5 & -5.9 & -32.1 & -2.5 & -1.0 & -4.8 & -1.3 & -0.5 & -2.5 \\
\hline $\begin{array}{l}\text { Trinidad and } \\
\text { Tobago }\end{array}$ & -1.2 & -0.5 & -2.3 & -0.5 & -0.2 & -1.1 & -0.1 & 0.0 & -0.2 & 0.0 & 0.0 & -0.1 \\
\hline Turkey & -36.5 & -14.8 & -71.2 & -16.6 & -6.3 & -34.5 & -2.7 & -1.1 & -5.2 & -1.4 & -0.6 & -2.7 \\
\hline $\begin{array}{l}\text { United Arab } \\
\text { Emirates }\end{array}$ & -20.4 & -8.3 & -39.7 & -9.3 & -3.5 & -19.3 & -1.5 & -0.6 & -2.9 & -0.8 & -0.3 & -1.5 \\
\hline Uruguay & -2.7 & -1.1 & -5.3 & -1.2 & -0.5 & -2.6 & -0.2 & -0.1 & -0.4 & -0.1 & 0.0 & -0.2 \\
\hline
\end{tabular}

Table B.3. Change in real annual GDP in \$bn relative to baseline scenario - Middle-income countries

\begin{tabular}{|l|l|l|l|l|l|l|l|l|l|l|l|l|}
\hline \multicolumn{7}{|c|}{ Scenario 1 } & \multicolumn{7}{|c|}{ Scenario 2 } & \multicolumn{3}{l}{ Scenario 3 } & \multicolumn{3}{l|}{ Scenario 4 } \\
\hline & M & L & H & M & L & H & M & L & H & M & L & H \\
\hline $\begin{array}{l}\text { Middle } \\
\text { income }\end{array}$ & -146.8 & -60.0 & -283.2 & -64.5 & -25.0 & -132.5 & -29.9 & -10.6 & -66.4 & -5.9 & -2.4 & -11.4 \\
\hline Albania & -1.0 & -0.4 & -2.0 & -0.4 & -0.2 & -0.9 & -0.2 & -0.1 & -0.5 & 0.0 & 0.0 & -0.1 \\
\hline Argentina & -29.8 & -12.2 & -57.5 & -13.1 & -5.1 & -26.9 & -6.1 & -2.1 & -13.5 & -1.2 & -0.5 & -2.3 \\
\hline Armenia & -0.9 & -0.4 & -1.7 & -0.4 & -0.2 & -0.8 & -0.2 & -0.1 & -0.4 & 0.0 & 0.0 & -0.1 \\
\hline Azerbaijan & -3.2 & -1.3 & -6.1 & -1.4 & -0.5 & -2.9 & -0.6 & -0.2 & -1.4 & -0.1 & -0.1 & -0.2 \\
\hline Belarus & -4.2 & -1.7 & -8.1 & -1.8 & -0.7 & -3.8 & -0.8 & -0.3 & -1.9 & -0.2 & -0.1 & -0.3 \\
\hline $\begin{array}{l}\text { Bosnia and } \\
\text { Herzegovina }\end{array}$ & -1.3 & -0.5 & -2.6 & -0.6 & -0.2 & -1.2 & -0.3 & -0.1 & -0.6 & -0.1 & 0.0 & -0.1 \\
\hline Botswana & -1.2 & -0.5 & -2.3 & -0.5 & -0.2 & -1.1 & -0.2 & -0.1 & -0.5 & 0.0 & 0.0 & -0.1 \\
\hline
\end{tabular}




\begin{tabular}{|c|c|c|c|c|c|c|c|c|c|c|c|c|}
\hline & \multicolumn{3}{|c|}{ Scenario 1} & \multicolumn{3}{|c|}{ Scenario 2} & \multicolumn{3}{|c|}{ Scenario 3} & \multicolumn{3}{|c|}{ Scenario 4} \\
\hline & M & L & $\mathrm{H}$ & M & L & $\mathrm{H}$ & M & L & $\mathrm{H}$ & M & L & $\mathrm{H}$ \\
\hline $\begin{array}{l}\text { Dominican } \\
\text { Republic }\end{array}$ & -5.9 & -2.4 & -11.4 & -2.6 & -1.0 & -5.3 & -1.2 & -0.4 & -2.7 & -0.2 & -0.1 & -0.5 \\
\hline Ecuador & -7.1 & -2.9 & -13.7 & -3.1 & -1.2 & -6.4 & -1.4 & -0.5 & -3.2 & -0.3 & -0.1 & -0.6 \\
\hline Georgia & -1.2 & -0.5 & -2.3 & -0.5 & -0.2 & -1.1 & -0.2 & -0.1 & -0.5 & 0.0 & 0.0 & -0.1 \\
\hline Guatemala & -5.1 & -2.1 & -9.8 & -2.2 & -0.9 & -4.6 & -1.0 & -0.4 & -2.3 & -0.2 & -0.1 & -0.4 \\
\hline Jamaica & -1.1 & -0.4 & -2.1 & -0.5 & -0.2 & -1.0 & -0.2 & -0.1 & -0.5 & 0.0 & 0.0 & -0.1 \\
\hline Jordan & -2.9 & -1.2 & -5.6 & -1.3 & -0.5 & -2.6 & -0.6 & -0.2 & -1.3 & -0.1 & 0.0 & -0.2 \\
\hline Kazakhstan & -11.9 & -4.9 & -23.0 & -5.2 & -2.0 & -10.8 & -2.4 & -0.9 & -5.4 & -0.5 & -0.2 & -0.9 \\
\hline Moldova & -0.8 & -0.3 & -1.5 & -0.3 & -0.1 & -0.7 & -0.2 & -0.1 & -0.4 & 0.0 & 0.0 & -0.1 \\
\hline Montenegro & -0.4 & -0.1 & -0.7 & -0.2 & -0.1 & -0.3 & -0.1 & 0.0 & -0.2 & 0.0 & 0.0 & 0.0 \\
\hline Namibia & -0.8 & -0.3 & -1.6 & -0.4 & -0.1 & -0.7 & -0.2 & -0.1 & -0.4 & 0.0 & 0.0 & -0.1 \\
\hline $\begin{array}{l}\text { North } \\
\text { Macedonia }\end{array}$ & -0.8 & -0.3 & -1.6 & -0.4 & -0.1 & -0.8 & -0.2 & -0.1 & -0.4 & 0.0 & 0.0 & -0.1 \\
\hline Paraguay & -2.5 & -1.0 & -4.9 & -1.1 & -0.4 & -2.3 & -0.5 & -0.2 & -1.1 & -0.1 & 0.0 & -0.2 \\
\hline Peru & -15.0 & -6.1 & -29.0 & -6.6 & -2.6 & -13.6 & -3.1 & -1.1 & -6.8 & -0.6 & -0.2 & -1.2 \\
\hline Serbia & -3.4 & -1.4 & -6.6 & -1.5 & -0.6 & -3.1 & -0.7 & -0.2 & -1.5 & -0.1 & -0.1 & -0.3 \\
\hline Thailand & -36.0 & -14.7 & -69.5 & -15.8 & -6.1 & -32.5 & -7.3 & -2.6 & -16.3 & -1.4 & -0.6 & -2.8 \\
\hline Ukraine & -10.2 & -4.2 & -19.7 & -4.5 & -1.7 & -9.2 & -2.1 & -0.7 & -4.6 & -0.4 & -0.2 & -0.8 \\
\hline
\end{tabular}

Table B.4. Change in real annual GDP in \$bn relative to baseline scenario - Low-income countries

\begin{tabular}{|l|l|l|l|l|l|l|l|l|l|l|l|l|}
\hline \multicolumn{7}{|c|}{} & \multicolumn{7}{|c|}{ Scenario 1 } & \multicolumn{7}{c|}{ Scenario 2 } & \multicolumn{3}{c|}{ Scenario 3 } & \multicolumn{3}{l|}{ Scenario 4} \\
\hline & M & L & H & M & L & H & M & L & H & M & L & H \\
\hline Low income & -200.3 & -81.8 & -386.8 & -82.0 & -31.7 & -168.0 & -35.3 & -11.5 & -86.0 & -27.9 & -8.5 & -71.5 \\
\hline Afghanistan & -1.0 & -0.4 & -2.0 & -0.4 & -0.2 & -0.9 & -0.2 & -0.1 & -0.4 & -0.1 & 0.0 & -0.4 \\
\hline Algeria & -9.1 & -3.7 & -17.5 & -3.7 & -1.4 & -7.6 & -1.6 & -0.5 & -3.9 & -1.3 & -0.4 & -3.2 \\
\hline Angola & -5.1 & -2.1 & -9.8 & -2.1 & -0.8 & -4.2 & -0.9 & -0.3 & -2.2 & -0.7 & -0.2 & -1.8 \\
\hline Bangladesh & -16.2 & -6.6 & -31.2 & -6.6 & -2.6 & -13.6 & -2.9 & -0.9 & -6.9 & -2.3 & -0.7 & -5.8 \\
\hline Belize & -0.1 & 0.0 & -0.2 & 0.0 & 0.0 & -0.1 & 0.0 & 0.0 & 0.0 & 0.0 & 0.0 & 0.0 \\
\hline Benin & -0.8 & -0.3 & -1.5 & -0.3 & -0.1 & -0.6 & -0.1 & 0.0 & -0.3 & -0.1 & 0.0 & -0.3 \\
\hline Bhutan & -0.1 & -0.1 & -0.3 & -0.1 & 0.0 & -0.1 & 0.0 & 0.0 & -0.1 & 0.0 & 0.0 & 0.0 \\
\hline
\end{tabular}




\begin{tabular}{|c|c|c|c|c|c|c|c|c|c|c|c|c|}
\hline & \multicolumn{3}{|c|}{ Scenario 1} & \multicolumn{3}{|c|}{ Scenario 2} & \multicolumn{3}{|c|}{ Scenario 3} & \multicolumn{3}{|c|}{ Scenario 4} \\
\hline & M & L & $\mathrm{H}$ & M & $L$ & $\mathrm{H}$ & M & L & $\mathrm{H}$ & M & L & $\mathrm{H}$ \\
\hline Bolivia & -2.2 & -0.9 & -4.2 & -0.9 & -0.3 & -1.8 & -0.4 & -0.1 & -0.9 & -0.3 & -0.1 & -0.8 \\
\hline Burkina Faso & -0.8 & -0.3 & -1.6 & -0.3 & -0.1 & -0.7 & -0.1 & 0.0 & -0.4 & -0.1 & 0.0 & -0.3 \\
\hline Burundi & -0.2 & -0.1 & -0.3 & -0.1 & 0.0 & -0.1 & 0.0 & 0.0 & -0.1 & 0.0 & 0.0 & -0.1 \\
\hline Cambodia & -1.4 & -0.6 & -2.8 & -0.6 & -0.2 & -1.2 & -0.3 & -0.1 & -0.6 & -0.2 & -0.1 & -0.5 \\
\hline Cameroon & -2.1 & -0.8 & -4.0 & -0.8 & -0.3 & -1.7 & -0.4 & -0.1 & -0.9 & -0.3 & -0.1 & -0.7 \\
\hline $\begin{array}{l}\text { Central } \\
\text { African } \\
\text { Republic }\end{array}$ & -0.1 & 0.0 & -0.2 & 0.0 & 0.0 & -0.1 & 0.0 & 0.0 & -0.1 & 0.0 & 0.0 & 0.0 \\
\hline Chad & -0.6 & -0.2 & -1.2 & -0.2 & -0.1 & -0.5 & -0.1 & 0.0 & -0.3 & -0.1 & 0.0 & -0.2 \\
\hline $\begin{array}{l}\text { Congo, Dem. } \\
\text { Rep. }\end{array}$ & -2.5 & -1.0 & -4.9 & -1.0 & -0.4 & -2.1 & -0.4 & -0.1 & -1.1 & -0.4 & -0.1 & -0.9 \\
\hline Congo, Rep. & -0.6 & -0.2 & -1.1 & -0.2 & -0.1 & -0.5 & -0.1 & 0.0 & -0.2 & -0.1 & 0.0 & -0.2 \\
\hline Cote d'Ivoire & -3.1 & -1.3 & -6.1 & -1.3 & -0.5 & -2.6 & -0.6 & -0.2 & -1.4 & -0.4 & -0.1 & -1.1 \\
\hline Djibouti & -0.2 & -0.1 & -0.3 & -0.1 & 0.0 & -0.1 & 0.0 & 0.0 & -0.1 & 0.0 & 0.0 & -0.1 \\
\hline El Salvador & -1.4 & -0.6 & -2.8 & -0.6 & -0.2 & -1.2 & -0.3 & -0.1 & -0.6 & -0.2 & -0.1 & -0.5 \\
\hline $\begin{array}{l}\text { Equatorial } \\
\text { Guinea }\end{array}$ & -0.6 & -0.2 & -1.1 & -0.2 & -0.1 & -0.5 & -0.1 & 0.0 & -0.3 & -0.1 & 0.0 & -0.2 \\
\hline Eswatini & -0.2 & -0.1 & -0.5 & -0.1 & 0.0 & -0.2 & 0.0 & 0.0 & -0.1 & 0.0 & 0.0 & -0.1 \\
\hline Ethiopia & -5.1 & -2.1 & -9.9 & -2.1 & -0.8 & -4.3 & -0.9 & -0.3 & -2.2 & -0.7 & -0.2 & -1.8 \\
\hline Gabon & -0.9 & -0.4 & -1.7 & -0.4 & -0.1 & -0.7 & -0.2 & -0.1 & -0.4 & -0.1 & 0.0 & -0.3 \\
\hline Ghana & -3.6 & -1.5 & -6.9 & -1.5 & -0.6 & -3.0 & -0.6 & -0.2 & -1.5 & -0.5 & -0.2 & -1.3 \\
\hline Guinea & -0.7 & -0.3 & -1.4 & -0.3 & -0.1 & -0.6 & -0.1 & 0.0 & -0.3 & -0.1 & 0.0 & -0.3 \\
\hline $\begin{array}{l}\text { Guinea- } \\
\text { Bissau }\end{array}$ & -0.1 & 0.0 & -0.1 & 0.0 & 0.0 & -0.1 & 0.0 & 0.0 & 0.0 & 0.0 & 0.0 & 0.0 \\
\hline Guyana & -0.2 & -0.1 & -0.4 & -0.1 & 0.0 & -0.2 & 0.0 & 0.0 & -0.1 & 0.0 & 0.0 & -0.1 \\
\hline Haiti & -0.5 & -0.2 & -0.9 & -0.2 & -0.1 & -0.4 & -0.1 & 0.0 & -0.2 & -0.1 & 0.0 & -0.2 \\
\hline Honduras & -1.3 & -0.5 & -2.6 & -0.5 & -0.2 & -1.1 & -0.2 & -0.1 & -0.6 & -0.2 & -0.1 & -0.5 \\
\hline Iraq & -12.5 & -5.1 & -24.2 & -5.1 & -2.0 & -10.5 & -2.2 & -0.7 & -5.4 & -1.7 & -0.5 & -4.5 \\
\hline Kenya & -5.1 & -2.1 & -9.9 & -2.1 & -0.8 & -4.3 & -0.9 & -0.3 & -2.2 & -0.7 & -0.2 & -1.8 \\
\hline $\begin{array}{l}\text { Kyrgyz } \\
\text { Republic }\end{array}$ & -0.5 & -0.2 & -0.9 & -0.2 & -0.1 & -0.4 & -0.1 & 0.0 & -0.2 & -0.1 & 0.0 & -0.2 \\
\hline Lebanon & -2.9 & -1.2 & -5.5 & -1.2 & -0.5 & -2.4 & -0.5 & -0.2 & -1.2 & -0.4 & -0.1 & -1.0 \\
\hline Lesotho & -0.1 & -0.1 & -0.3 & -0.1 & 0.0 & -0.1 & 0.0 & 0.0 & -0.1 & 0.0 & 0.0 & 0.0 \\
\hline
\end{tabular}




\begin{tabular}{|c|c|c|c|c|c|c|c|c|c|c|c|c|}
\hline & \multicolumn{3}{|c|}{ Scenario 1} & \multicolumn{3}{|c|}{ Scenario 2} & \multicolumn{3}{|c|}{ Scenario 3} & \multicolumn{3}{|c|}{ Scenario 4} \\
\hline & M & $\mathbf{L}$ & $\mathrm{H}$ & M & $\mathbf{L}$ & $\mathrm{H}$ & M & L & $\mathrm{H}$ & M & $L$ & $\mathrm{H}$ \\
\hline Liberia & -0.2 & -0.1 & -0.3 & -0.1 & 0.0 & -0.1 & 0.0 & 0.0 & -0.1 & 0.0 & 0.0 & -0.1 \\
\hline Libya & -2.8 & -1.1 & -5.4 & -1.1 & -0.4 & -2.3 & -0.5 & -0.2 & -1.2 & -0.4 & -0.1 & -1.0 \\
\hline Madagascar & -0.8 & -0.3 & -1.5 & -0.3 & -0.1 & -0.6 & -0.1 & 0.0 & -0.3 & -0.1 & 0.0 & -0.3 \\
\hline Malawi & -0.4 & -0.2 & -0.8 & -0.2 & -0.1 & -0.3 & -0.1 & 0.0 & -0.2 & -0.1 & 0.0 & -0.1 \\
\hline Mali & -0.9 & -0.4 & -1.8 & -0.4 & -0.1 & -0.8 & -0.2 & -0.1 & -0.4 & -0.1 & 0.0 & -0.3 \\
\hline Mauritania & -0.4 & -0.2 & -0.8 & -0.2 & -0.1 & -0.3 & -0.1 & 0.0 & -0.2 & -0.1 & 0.0 & -0.1 \\
\hline Mongolia & -0.7 & -0.3 & -1.4 & -0.3 & -0.1 & -0.6 & -0.1 & 0.0 & -0.3 & -0.1 & 0.0 & -0.3 \\
\hline Morocco & -6.3 & -2.6 & -12.3 & -2.6 & -1.0 & -5.3 & -1.1 & -0.4 & -2.7 & -0.9 & -0.3 & -2.3 \\
\hline Mozambique & -0.8 & -0.3 & -1.5 & -0.3 & -0.1 & -0.7 & -0.1 & 0.0 & -0.3 & -0.1 & 0.0 & -0.3 \\
\hline Myanmar & -4.1 & -1.7 & -7.9 & -1.7 & -0.6 & -3.4 & -0.7 & -0.2 & -1.7 & -0.6 & -0.2 & -1.5 \\
\hline Nepal & -1.6 & -0.7 & -3.2 & -0.7 & -0.3 & -1.4 & -0.3 & -0.1 & -0.7 & -0.2 & -0.1 & -0.6 \\
\hline Nicaragua & -0.7 & -0.3 & -1.3 & -0.3 & -0.1 & -0.6 & -0.1 & 0.0 & -0.3 & -0.1 & 0.0 & -0.2 \\
\hline Niger & -0.7 & -0.3 & -1.3 & -0.3 & -0.1 & -0.6 & -0.1 & 0.0 & -0.3 & -0.1 & 0.0 & -0.2 \\
\hline Nigeria & -24.0 & -9.8 & -46.3 & -9.8 & -3.8 & -20.1 & -4.2 & -1.4 & -10.3 & -3.3 & -1.0 & -8.6 \\
\hline Pakistan & -14.9 & -6.1 & -28.7 & -6.1 & -2.4 & -12.5 & -2.6 & -0.9 & -6.4 & -2.1 & -0.6 & -5.3 \\
\hline Philippines & -20.1 & -8.2 & -38.9 & -8.2 & -3.2 & -16.9 & -3.5 & -1.2 & -8.7 & -2.8 & -0.9 & -7.2 \\
\hline Rwanda & -0.5 & -0.2 & -1.0 & -0.2 & -0.1 & -0.5 & -0.1 & 0.0 & -0.2 & -0.1 & 0.0 & -0.2 \\
\hline Senegal & -1.3 & -0.5 & -2.4 & -0.5 & -0.2 & -1.1 & -0.2 & -0.1 & -0.5 & -0.2 & -0.1 & -0.5 \\
\hline Sierra Leone & -0.2 & -0.1 & -0.4 & -0.1 & 0.0 & -0.2 & 0.0 & 0.0 & -0.1 & 0.0 & 0.0 & -0.1 \\
\hline Sri Lanka & -4.5 & -1.8 & -8.7 & -1.8 & -0.7 & -3.8 & -0.8 & -0.3 & -1.9 & -0.6 & -0.2 & -1.6 \\
\hline Sudan & -1.0 & -0.4 & -2.0 & -0.4 & -0.2 & -0.8 & -0.2 & -0.1 & -0.4 & -0.1 & 0.0 & -0.4 \\
\hline Suriname & -0.2 & -0.1 & -0.4 & -0.1 & 0.0 & -0.2 & 0.0 & 0.0 & -0.1 & 0.0 & 0.0 & -0.1 \\
\hline Tajikistan & -0.4 & -0.2 & -0.8 & -0.2 & -0.1 & -0.4 & -0.1 & 0.0 & -0.2 & -0.1 & 0.0 & -0.2 \\
\hline Tanzania & -3.4 & -1.4 & -6.5 & -1.4 & -0.5 & -2.8 & -0.6 & -0.2 & -1.5 & -0.5 & -0.1 & -1.2 \\
\hline Timor-Leste & -0.1 & 0.0 & -0.2 & 0.0 & 0.0 & -0.1 & 0.0 & 0.0 & 0.0 & 0.0 & 0.0 & 0.0 \\
\hline Togo & -0.3 & -0.1 & -0.6 & -0.1 & 0.0 & -0.2 & -0.1 & 0.0 & -0.1 & 0.0 & 0.0 & -0.1 \\
\hline Tunisia & -2.1 & -0.8 & -4.0 & -0.8 & -0.3 & -1.7 & -0.4 & -0.1 & -0.9 & -0.3 & -0.1 & -0.7 \\
\hline Turkmenistan & -2.2 & -0.9 & -4.2 & -0.9 & -0.3 & -1.8 & -0.4 & -0.1 & -0.9 & -0.3 & -0.1 & -0.8 \\
\hline Uganda & -1.8 & -0.8 & -3.5 & -0.8 & -0.3 & -1.5 & -0.3 & -0.1 & -0.8 & -0.3 & -0.1 & -0.7 \\
\hline Uzbekistan & -3.1 & -1.3 & -6.0 & -1.3 & -0.5 & -2.6 & -0.5 & -0.2 & -1.3 & -0.4 & -0.1 & -1.1 \\
\hline
\end{tabular}




\begin{tabular}{|l|l|l|l|l|l|l|l|l|l|l|l|l|}
\hline & \multicolumn{3}{|c|}{ Scenario 1 } & \multicolumn{3}{c|}{ Scenario 2 } & \multicolumn{3}{c|}{ Scenario 3 } & \multicolumn{3}{|c|}{ Scenario 4 } \\
\hline & M & L & H & M & L & H & M & L & H & M & L & H \\
\hline Vietnam & -14.0 & -5.7 & -27.0 & -5.7 & -2.2 & -11.7 & -2.5 & -0.8 & -6.0 & -2.0 & -0.6 & -5.0 \\
\hline Yemen, Rep. & -1.5 & -0.6 & -2.8 & -0.6 & -0.2 & -1.2 & -0.3 & -0.1 & -0.6 & -0.2 & -0.1 & -0.5 \\
\hline Zambia & -1.2 & -0.5 & -2.4 & -0.5 & -0.2 & -1.0 & -0.2 & -0.1 & -0.5 & -0.2 & -0.1 & -0.4 \\
\hline Zimbabwe & -1.1 & -0.5 & -2.2 & -0.5 & -0.2 & -1.0 & -0.2 & -0.1 & -0.5 & -0.2 & 0.0 & -0.4 \\
\hline
\end{tabular}

